\title{
La transición al siglo XIX en la Catedral de Jaén: el maestro de capilla Ramón Garay (1761-1823)
}

\author{
The Transition to 19th Century at the Jaén Cathedral: The Chapel Master \\ Ramón Garay (1761-1823)
}

\author{
Paulino Capdepón Verdú \\ Universidad de Castilla-La Mancha \\ Centro de Investigación y Documentación Musical- \\ Unidad Asociada al CSIC \\ paulino.capdepon@uclm.es \\ ORCID iD: https://orcid.org/0000-0001-6509-3496
}

\section{RESUMEN}

Este artículo se centra en el estudio de la trayectoria personal y artística de uno de los compositores más representativos de la España de la segunda mitad del siglo XVIII y primer tercio del siglo XIX. Ramón Garay, nacido en 1761 en Asturias, ejerció el cargo de Maestro de capilla de la Catedral de Jaén durante 36 fructíferos años que vieron nacer una extraordinaria producción de obras musicales al servicio de la liturgia de dicha Catedral. Pero asimismo la figura de Garay sobresale por haber sido uno de los pioneros en la introducción del género sinfónico en España.

Palabras clave: Garay, maestro de capilla, catedral, sinfonía, Jaén.

\begin{abstract}
This article focuses on the study of the personal and artistic career of one of the most representative Spanish composers in the second half of 18th and the first third of 19th century. Ramón Garay, born in 1761 in Asturias, was Chapel Master of the Cathedral of Jaén for 36 fruitful years that saw the birth of an extraordinary output of musical works at the service of the liturgy of the Cathedral. But Garay also stands out for having been one of the pioneers in the introduction of the symphonic genre in Spain.
\end{abstract}

Key words: Garay, Chapel Master, Cathedral, Symphony, Jaén. 


\section{LA TRANSICIÓN AL SIGLO XIX EN LA CATEDRAL DE JAÉN: EL MAESTRO DE CAPILLA RAMÓN GARAY (1761-1823)}

Capdepón Verdú, P. (2018). La transición al siglo XIX en la Catedral de Jaén: el maestro de capilla Ramón Garay (1761-1823). Cuadernos de Investigación Musical, 2018, 6 (extraordinario), 156-194.

DOI: $10.18239 /$ invesmusic.v0i0.1944

\section{INTRODUCCIÓN}

La España del siglo XVIII experimenta uno de los periodos más gloriosos de la música eclesiástica gracias a la actividad creativa de los maestros de capilla que trabajan dirigiendo las distintas capillas musicales de catedrales, colegiatas, monasterios o iglesias parroquiales. En ese marco de apogeo cultural y musical destaca la Catedral de Jaén, que desempeñó un relevante papel, atrayendo a un elevado número de maestros, organistas, cantores, instrumentistas, sochantres, salmistas, etc., procedentes de toda España. Precisamente, uno de los más prolíficos compositores españoles nacidos en la segunda mitad de aquel siglo fue el asturiano Ramón Garay, quien tras estudiar en Avilés, Oviedo y Madrid, se trasladó a Jaén con el fin de optar a su primer magisterio importante, logrando el puesto a pesar de la inicial polémica suscitada con el maestro censor, Jaime Balius, a la sazón Maestro de capilla de la Catedral de Córdoba. En Jaén desarrollará Garay una brillante carrera compositiva que permitió que gozara en vida de un sólido prestigio, como lo demuestra su presencia en varios archivos españoles o su invitación a la corte de Fernando VII en Madrid. Pero, como podremos comprobar a lo largo de este artículo, su inspiración compositiva no se limitó a los típicos géneros vocales religiosos en latín o castellano, sino que, constituyendo una verdadera excepción llamativa, nos ha legado diez sinfonías que suponen uno de los logros más acabados en este ámbito, nada habitual entre los maestros de capilla españoles de la época.

\section{ESTADO DE LA CUESTIÓN}

Hasta finales del siglo pasado, la biografía del compositor Ramón Garay, uno de los precursores del quehacer sinfónico español en la segunda mitad del siglo XVIII, apenas era conocida, mientras que su obra musical apenas se había interpretado o grabado. Así por ejemplo, en las últimas ediciones de las principales enciclopedias y diccionarios musicales de consulta a nivel internacional, no se incluyó un artículo referente a su figura: la segunda edición de la enciclopedia Die Musik in Geschichte und Gegenwart (Finscher, 1994-2007) y la segunda edición The New Grove Dictionary of Music and Musicians (Sadie, 2001), lo cual indica el trabajo de reivindicación y recuperación de la obra de este compositor que es todavía es necesario llevar a cabo․ Afortunadamente, un artículo sobre Garay sí fue incluido en el volumen V del Diccionario de la Música Española e Hispanoamericana, que venía a recopilar las investigaciones que hasta el momento había emprendido Pedro Jiménez (Jiménez, 2000).

\footnotetext{
${ }_{1}^{1}$ Situación que se repite en otras obras enciclopédicas como Suárez 1936-1959, o bien Cañada 1970-1999.
} 


\section{PaUlino CAPDEPón Verdú}

A pesar de ello, puede afirmarse que la personalidad humana y musical de Ramón Garay ha atraído el interés de numerosos autores e investigadores: uno de los primeros fue el canónigo de la Catedral de Jaén, José Martínez Mazas, según la recopilación de sus escritos, llevada a cabo en 1857 por otro canónigo giennense, Manuel Muñoz y Garnica (Muñoz y Garnica, 1857). Por su parte, Baltasar Saldoni incluía las siguientes breves líneas sobre el compositor asturiano:

Garay, don Ramón: racionero y maestro de capilla de la santa Iglesia de Jaén. El día 9 de enero de 1795 publicó en Madrid, de su composición, una Misa a dúo, con acompañamiento de órgano obligado; el día 27 de noviembre, del mismo año otra Misa, a tres y siete voces, con violines, trompas y bajos, y el día 8 de junio de 1802 dos motetes y dos villancicos al Santísimo, a solo y a cinco voces, con dos violines y bajo (Saldoni, 1881: 112).

Por lo que respecta a los Papeles Barbieri, Garay es citado en su calidad de maestro de capilla de la catedral de Jaén, lo cual viene a corroborar la estima que seguía gozando en la segunda mitad del siglo XIX:

Garay, Ramón. Presbítero, racionero y Maestro de Capilla de la Catedral de Jaén. Algunas de sus obras existentes en El Escorial tienen la fecha de 1785, y en los Diarios de Madrid, desde septiembre de 1793 hasta junio de 1802, se hallan los anuncios de venta de varias obras de música religiosa de su autor (MSS 14.084) (Casares, 1986: 221).

Además, gracias a dichos Papeles se conoce el hecho de que el Diario de Madrid anunciaba el 19 de septiembre de 1793 la publicación de una "Misa Nueva" de Garay: "Maestro de capilla de la Catedral de Jaén. Una Misa Nueva a dúo con órgano obligado, anunciada en el Diario de Madrid del 19 de septiembre de 1793 (MSS 14.030) (Casares, 1986: 221). La noticia aparecida en el Diario de Madrid a la que se re ere Barbieri es la que a continuación reproducimos:

En la librería de Correa, frente a las gradas de San Felipe el Real, se halla todo género de música, tanto vocal como instrumental, y nuevamente para guitarra, 24 sonatas de vatios autores; asimismo, una Misa nueva a dúo, con acompañamiento de órgano obligado, propia para los conventos y demás iglesias, compuesta por el Sr. Don Ramón Garay, Maestro de Capilla de la Catedral de Jaén (Diario de Madrid, 19 de septiembre de 1793)².

${ }^{2}$ Facsímil de la noticia recogido en Jiménez, 2011: 37. 


\section{LA TRANSICIÓN AL SIGLO XIX EN LA CATEDRAL DE JAÉN: EL MAESTRO DE CAPILLA RAMÓN GARAY (1761-1823)}

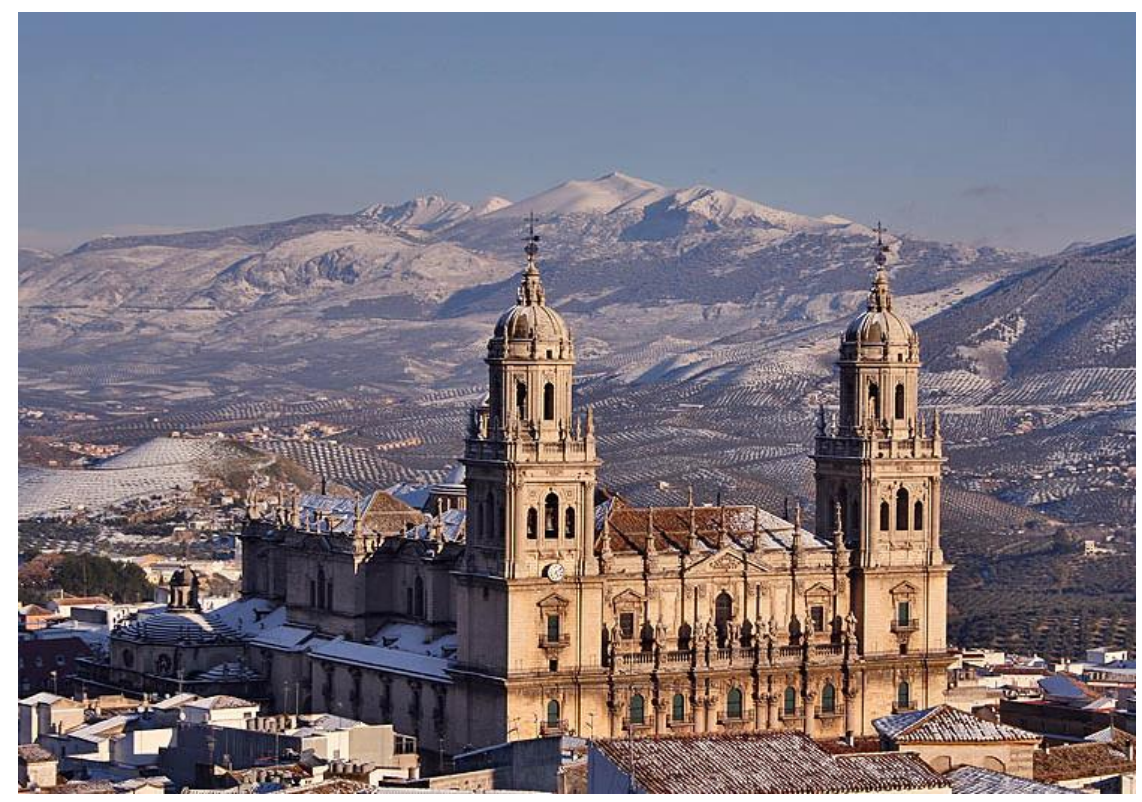

Fig. 1: Catedral de Jaén.

Ya en el siglo XX, Pedro Jiménez cita dos revistas que a comienzos de dicho siglo recogían sendas noticias relativas a la ópera de Garay Compendio sucinto de la Revolución Española en la revista granadina La Alhambra (n $\left.{ }^{\circ} 24,1908: 193-195\right)$ así como en la revista de Jaén Don Lope de Sosa (nº 9, 1913: 261)3.

Una de las obras clásicas de la historiografía española, la aportación de Rafael Mitjana a la Historie de la Musique de Lavignac, ignora sin embargo la actividad musical de Ramón Garay, lo cual preludiaba el esfuerzo que sería necesario emprender para recuperar la vida y obra musical de Ramón Garay4. Por otra parte, el primer catálogo del archivo de música del Palacio Real de Madrid, de García Marcellán, publicado en 1938, incorporaba un oratorio al santísimo y se ofrecían sucintas noticias biográficas de Garay, una de ellas conteniendo un error de bulto pues en 1750 no podía ser racionero y maestro de capilla de Jaén, ya que todavía faltaban once años para que naciera en Avilés:

Compositor del siglo XVIII. El año 1750 era racionero y maestro de Capilla de la Catedral de Jaén. Compuso solamente música religiosa: misas, entre ellas una a tres y siete voces con violines, trompas, trompas y bajo; motetes, villancicos al Santísimo, a solo y cinco voces con violines y bajo, y un oratorio a cuatro voces con orquesta (García Marcellán, 1938: $179)^{5}$.

\footnotetext{
${ }^{3}$ Citado en Jiménez, 2011: 36.

4 Mitjana 1920. Otras historias referentes a la música española que tampoco han tenido en cuenta la figura de Ramón Garay han sido las siguientes: Soriano Fuertes, 1855-1859; Anglés, 1941; Kastner, 1941; Chase, 1944; Subirá, 1953; Salazar, 1972; Le Bordays, 1978. Por otra parte, otros estudios generales sobre el siglo XVIII tampoco hacen referencia alguna a Garay: Hamilton, 1937; Wellesz y Sternfeld, 1973; Dahlhaus, 1985. Boyd y Carreras, 2000; Keefe, 2009 o Schmierer, 2015.

5 Vuelve a citarse dicho oratorio de Garay en Peris, 1993: 284.
} 


\section{PAUlino CAPDEPón Verdú}

Durante la segunda mitad del siglo XX, en el Diccionario de la Música Labor de Pena y Anglés, es referenciado Garay brevemente haciendo alusión a un reducido número de obras y sin citar la principal fuente para el conocimiento de su legado musical (el archivo de la catedral de Jaén):

Compositor español de fines del s. XVIII. Fue racionero y maestro de capilla de la catedral de Jaén. Obras: Missa a dúo y órg. Obligado (Madrid, 1795); Missa a 3 y 7 v. Con V., trompas y bajo (id, id.); 2 motetes y 2 villancicos al Santísimo Sacramento, a solo y a 5 v., con 2 V. En la catedral de Málaga se guardaban algunas obras mss. de este autor (Pena y Anglés, 1954: 1011-1012).

Sin embargo, otro importante diccionario de la misma época, (Ricart y Matas, 1956) y el suplemento "La música en España", que Higinio Anglés preparó para la edición de la Historia de la Música de Johannes Wolf (Anglés, 1965) omiten sorprendentemente la figura de Garay. Y tampoco es citado Garay en ninguna de las nueve ediciones de The Concise Baker's Biographical Dictionary of Musicians (Kuhn, 2007) ni en el Dizionario Enciclopedico Universale della Musica e dei Musicisti (Basso, 1983-2005). Por otra parte, dos importantes obras colectivas, la Historia de la Música de la Sociedad Italiana de Musicología (AA. VV: 1987) y el Diccionario biográfico de los grandes compositores de la Música (Honneger, 1994) ${ }^{6}$.

En épocas más recientes, uno de los primeros autores que estudió los comienzos de Garay y llamó la atención sobre su valía fue el canónigo Raúl Arias del Valle, antiguo archivero y director del archivo capitular de la catedral de Oviedo en un artículo publicado en la revista Papeles de Música (Arias del Valle, 1982) ${ }^{7}$ sin olvidar las aportaciones del cronista Justo Ureña y Hevia (2005). Un paso trascendental en el conocimiento de la obra de Garay tuvo lugar a comienzos de los años 80 del siglo pasado cuando el organista de la catedral de Jaén, Alfonso Medina Crespo, catalogó el archivo de música de la citada catedral: gracias a la magnífica labor llevada a cabo por el mencionado organista se pudo obtener una visión completa de la ingente producción musical de Ramón Garay. Dicho catálogo de música de la Catedral de Jaén estuvo disponible en la red hasta que finalmente fue publicado por el Centro de Documentación Musical de Andalucía en 20098. A ello es necesario añadir la benemérita labor llevada a cabo por el antiguo archivero de la Catedral giennense, el padre José Melgares (1997 y 2003).

Otro autor que desde los años 80 del siglo pasado ha contribuido decisivamente al redescubrimiento de Garay ha sido Antonio Martín Moreno, catedrático de musicología de la universidad de Granada, quien escribe lo siguiente en su excelente volumen $4^{\circ}$ de la Historia de la música española:

\footnotetext{
${ }^{6}$ La misma tendencia cabe observar en otras historias de la música generales, entre las que cabe citar: Abraham, 1986; Robertson y Stevens, 1993; Beltrando-Patier, 1996; Gallego, 1997; Mila, 1998; Dufourc, 2003; Honolka, 2005; Griffiths: 2009; Polo, 2011; Rebatet, 2012; Burkholder, Grout y Palisca, 2015.

${ }^{7}$ De este mismo autor, véase Arias del Valle, 1981 y 1990.

${ }^{8}$ De este mismo autor consúltense Medina, 1997, 1999, 1999a, 2000, 2002 y 2008.
} 


\section{LA TRANSICIÓN AL SIGLO XIX EN LA CATEDRAL DE JAÉN: EL MAESTRO DE CAPILLA RAMÓN GARAY (1761-1823)}

es uno de los autores más interesantes de las últimas décadas de nuestro siglo por haber cultivado la forma sonata que practica en sus 10 Sinfonías. Se conserva, además, una gran cantidad de sus obras como misas, vísperas, salmos, secuencias, responsorios, etc., en Jaén, y también hay obras suyas en El Escorial, Madrid, Oviedo, Málaga y otros archivos españoles (Martín Moreno, 1985: 203)ำ.

En otro orden de cosas, en la recuperación y estudio de la obra de Garay ha sido fundamental el trabajo desarrollado por Pedro Jiménez Cavallé, quien, gracias a toda una serie de artículos, monografías -y sobre todo, la edición de sus sinfonías completas en el Instituto Complutense de Ciencias Musicales de Madrid (Jiménez, 1996 y 2009)-, dio a conocer datos relevantes sobre su trayectoria biográfica y musical. Así por ejemplo, en su historia de la música giennense, Garay ocupaba el espacio que merecía como verdadero protagonista de la vida musical de la ciudad durante la segunda mitad del siglo XVIII y comienzo del siglo XIX (Jiménez, 1991) ${ }^{10}$. Gracias a la citada edición de sus sinfonías completas, se han podido programar la audición de varias de ellas desde que en 1985 se interpretara por primera vez en tiempos modernos la $5^{a}$ Sinfonía a cargo de la Orquesta Barroca del Festival de Granada bajo la dirección de Luis Remartínez, con ocasión del XXXIV Festival Internacional de Música y Danza de Granada, que por entonces dirigía el profesor Antonio Martín Moreno. Posteriormente agrupaciones como la Orquesta Barroca de Sevilla, la Orquesta de la Comunidad de Madrid, la Orquesta de Cámara de Israel o la Orquesta Concerto Brandemburg de Berlín han incorporado en sus programas sinfonías de Garay, mientras que la Orquesta de Córdoba, dirigida por José Luis Temes, llevó a cabo en 2010 la grabación completa de las diez sinfonías de Garay en el sello discográfico español Verso: son de gran interés las notas que el propio director de orquesta preparó para esta edición discográfica, que suponía la plena recuperación del legado sinfónico de Garay (Temes, 2010).

Un año después, en 2011 Manuel Filgaira daba a conocer datos esenciales sobre la genealogía y linaje de Ramón Garay, en un artículo publicado en el primer número de la Revista MAR (Música de Andalucía en la Red), revista musicológica dirigida por Antonio Martín Moreno (Filgaira, 2011). Asimismo en 2011, Pedro Jiménez publicaba una completa y muy interesante monografía sobre Ramón Garay, centrada especialmente en el estudio y análisis de sus diez sinfonías (Jiménez 2011). Ese mismos año nosotros publicábamos en la revista Cuadernos de Ilustración y Romanticismo un artículo de carácter introductorio sobre la vida y obra del compositor que protagoniza el presente artículo (Capdepón, 2011a). También de 2011 data la tesis doctoral de Rosario Montero, dedicada a la presencia de Haydn en España, en la que afirma que

\footnotetext{
${ }^{9}$ Del mismo autor consúltense asimismo Martín Moreno, 1981, 1983, 1984, 1985a, 1986 y 2000.

${ }^{10}$ Consúltense asimismo Jiménez Cavallé 1987, 1987a, 1988, 1998, 2000, 2009a y 2011a.
} 


\section{PAULINO CAPDEPón Verdú}

también se atribuyen a Garay (1761-1823) toda una serie de rasgos formales, tonales, instrumentales y estilísticos en sus Sinfonías que también se encuentran en la obras de Haydn, además de la coincidencia temática entre el Minué de la Quinta Sinfonía de Garay y el Allegro inicial de la $\mathrm{n}^{\circ} 16$ de Haydn. Este procedimiento de citar temáticamente a otro compositor era habitual en época de Haydn y, dado que hay veinticuatro sinfonías del compositor austriaco en el Archivo de la Catedral de Jaén, no es de extrañar que Garay citase alguna de ellas, lo cual a su vez prueba que eran sinfonías que durante su magisterio ya estaban en la catedral jiennense. Por otra parte, los rasgos que parecen ser exclusivos de Haydn y hallados por Pedro Jiménez Cavallé en la obra de Garay, podrían ser también comunes a otros compositores coetáneos o anteriores a Haydn, como Stamitz o Mozart, a través de los cuales se definieron los rasgos del estilo clásico y cuyas obras también se conservan en la catedral (Montero García, 2011).

Por su parte, en 2012 José López-Calo publicaba un monumental estudio sobre la música catedralicia española, dedicando amplio espacio al estudio de la personalidad musical del compositor asturiano (López-Calo, 2012). estado de la cuestión en torno a Ramón Garay se debe al volumen correspondiente al siglo XVIII de la Historia de la Música en España e Iberoamérica: hubiera sido una buena oportunidad para dar a conocer y valorar los conocimientos que hasta ahora se han recopilado sobre el compositor asturiano; lamentable- mente, tal oportunidad ha sido desaprovechada pues se limita este libro a la faceta sinfónica de Garay, sin ni siquiera citar los estudios de Pedro Jiménez ni mencionar en la bibliografía la edición de las sinfonías en dos volúmenes por parte del citado autor, lo cual no deja de ser inaudito (Leza, 2014) ${ }^{11}$. Independientemente de ello, en los últimos tiempos la obra vocal de Garay han concitado el interés de diversos grupos e instituciones. Así por ejemplo, en la edición de 2008 del XII Festival de Música Antigua de Úbeda y Baeza (Jaén) y con notas al programa de Juan Pablo Pacheco Torres, se reestrenó la ópera de Garay Compendio sucinto de la revolución española a cargo de La Grande Chapelle, dirigida por Albert Recasens, en el marco de los actos conmemorativos del bicentenario de la Guerra de la Independencia, auspiciados por la Sociedad Estatal de Conmemoraciones Culturales (Pacheco, 2008) ${ }^{12}$.

Más recientemente, la XXI edición del Festival de Arte Sacro se inauguró el 20 de febrero de 2011 con la interpretación del Oratorio al Santísimo en la Real Parroquia de San Ginés, a cargo del Grupo Camerata del Prado, bajo la dirección de Tomás Garrido, quien asimismo se encargó de redactar las notas al programa de mano ${ }^{13}$. Más recientemente se publicó la edición de su obra en castellano (Capdepón, 2016) si bien está pendiente de estudio y de publicación la amplísima aportación de Garay al campo de la música eclesiástica latina.

\footnotetext{
${ }^{11}$ Lo mismo ocurre con otro compositor capital del siglo XVIII español: el padre Antonio Soler, del cual se ignora en esta publicación fallida toda su obra vocal, tanto religiosa como teatral, ignorando la abundante bibliografía generada sobre tal cuestión, lo cual incide en las graves y numerosas lagunas de este libro.

12 Noticia de la que se hizo eco el artículo periodístico de Ramón Baragaño (2008). Sobre esta obra véase asimismo Pacheco 2008a, 2008b, 2010, mientras que la edición musical se encuentra en preparación.

13 http://www.madrid.org/artesacro/2011/espacios/01.html [consultado el 30 de marzo de 2018]
} 


\section{LA TRANSICIÓN AL SIGLO XIX EN LA CATEDRAL DE JAÉN:}

EL MAESTRO DE CAPILLA RAMÓN GARAY (1761-1823)

\section{TRAYECTORIA BIOGRÁFICA DE RAMÓN GARAY}

\subsection{NACIMIENTO EN AVILÉS}

Nacido en Avilés el 27 de enero de 1761, fue bautizado en la iglesia parroquial de Santo Tomás de Sabugo de su ciudad natal (Arias del Valle, 1982). El acta de bautismo dice así:

En veintisiete de enero de este año de mil setecientos sesenta y uno, don Fernando García Prada, con mi licencia, bautizó solemnemente, puso óleo y crisma a un niño, que le puso [por] nombre Ramón Fernando, hijo legítimo de Ramón Garay y de María Álvarez, vecinos de esta parroquia; fueron sus padrinos don Fernando Miranda y doña Teresa Cañedo, que no contrajo. El niño nació el mismo día, advertirles su obligación y cognación espiritual; y para que conste, lo firmo. Juan Fernández Siñériz y Trelles (Archivo de la Catedral de Jaén, legajo 511.) ${ }^{14}$.

Todos los aspectos sobre los orígenes de la familia de Ramón Garay han podido ser dilucidados gracias a la publicación de su expediente de limpieza de sangra con motivo de su admisión en la Catedral de Jaén como Maestro de capilla (Filgaira, 2011).

Probablemente recibió sus primeras lecciones musicales de su padre, a la sazón organista de la Basílica de Santa María la Real de Covadonga. Ureña y Hevia dice al respecto que gracias a sus cualidades vocales fue admitido en el Convento de la Merced de Avilés en calidad de niño de coro (Ureña y Hevia, 2005). Por su parte, Pedro Jiménez alude al respecto que el ingreso del joven Garay en el convento de la Merced tuvo lugar posiblemente alrededor de 1769, cuando contaba con ocho años e incluso pudo haberlo hecho con anterioridad; sigue diciendo Jiménez que apenas se conoce nada de esta etapa y de la vida musical del mencionado convento pero que podría suponerse que sus actividades estuvieron dirigidas a asentar su formación musical y religiosa así como al estudio de la gramática, participando en las ceremonias y festividades religiosas con intervención musical, las habituales en cualquier institución eclesiástica (Jiménez, 2011a: 56).

\footnotetext{
${ }^{14}$ Citado en Jiménez, 2011a: 533.
} 


\section{PaUlino CAPDEPón Verdú}

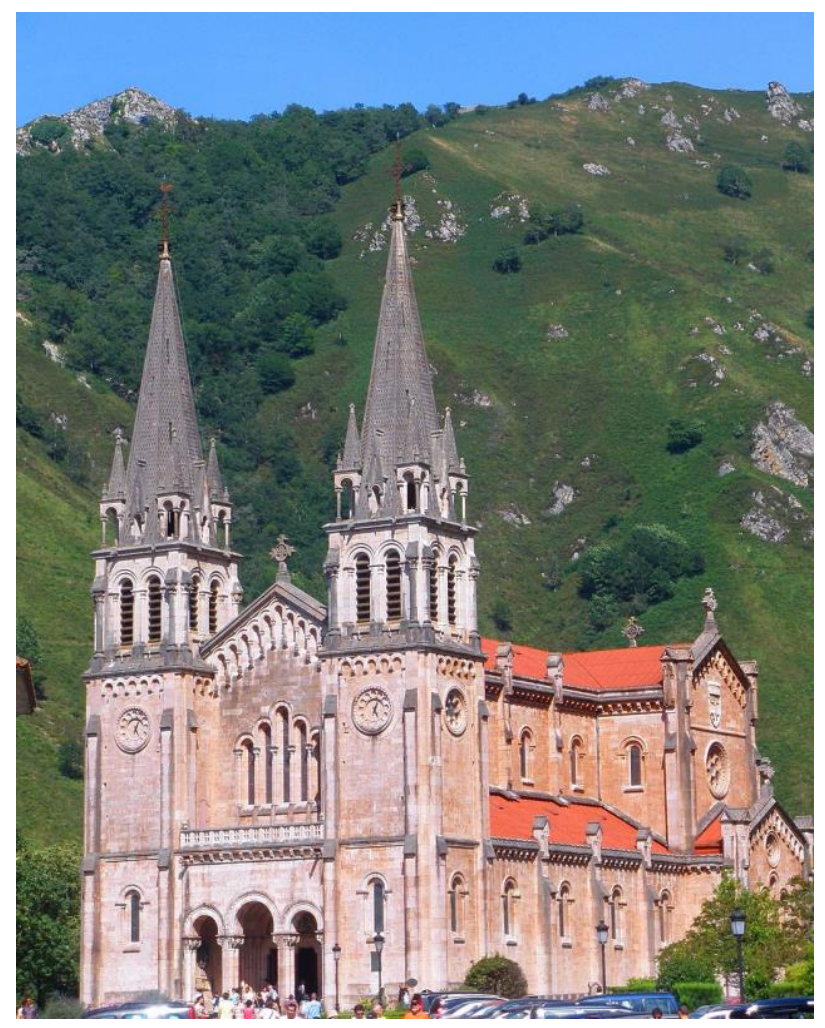

Fig. 2: Colegiata de Covadonga.

\subsection{EN LA CATEDRAL DE OVIEDO}

En 1779 ingresó como salmista en la catedral ovetense, tal como se recoge en la el acta capitular del 3 de diciembre de 1779: "Salmista admitido con cuatro reales de salario. Admítase a don Ramón Garay" (Arias del Valle, 1982). En opinión de Arias del Valle, el hecho de que fuera admitido no como niño de coro sino como salmista, indica con claridad que por entonces poseía una buena formación musical, seguramente adquirida con su padre, que regentaba la organistía de la Real Colegiata de Nuestra Señora de Covadonga (Archivo de la Catedral de Jaén [ACJ], Expediente de oposiciones al magisterio de capilla (17841787): Escrito de Juan Andrés de Lombide, 9 de noviembre de 1787), y ampliada durante los años de mozo de coro, transcurridos en el convento avilesino de la Merced, tal como comentábamos anteriormente.

Apenas existen datos en la catedral de Oviedo sobre la estancia de Garay: así por ejemplo, el 6 de febrero de 1781 fue despedido junto a los sacristanes y a los también salmistas Polledo y Rodríguez por faltas «no disimulables» en la función y entierro de José de Valledor, aunque cuatro días después Garay y Polledo fueron readmitidos porque el Cabildo se hizo cargo «de no haber sido tan culpables como se creyó». También los sacristanes fueron readmitidos, pero con la penitencia de estar «tres días continuos de manteo y bonete dentro de las rejas del coro con la compostura y modestia debidas" (Archivo de la Catedral de Oviedo [ACO], Actas capitulares, 9 de febrero de 1781. Citado en 


\section{LA TRANSICIÓN AL SIGLO XIX EN LA CATEDRAL DE JAÉN: \\ EL MAESTRO DE CAPILLA RAMÓN GARAY (1761-1823)}

Arias del Valle, 1982). A partir de 1783, Ramón Garay estudió con el organista de la Catedral de Oviedo, Juan Andrés Lombide ${ }^{15}$, futuro organista primero del Real Monasterio de la Encarnación en Madrid: "Mandose decir al organista que dé lecciones de órgano al salmista Ramón Garay, respecto está ya medianamente impuesto en este instrumento y le permita tocar en el segundo órgano, para que se vaya adiestrando" (ACO, Actas capitulares, 26 de julio de 1781. Citado en Arias del Valle, 1982).

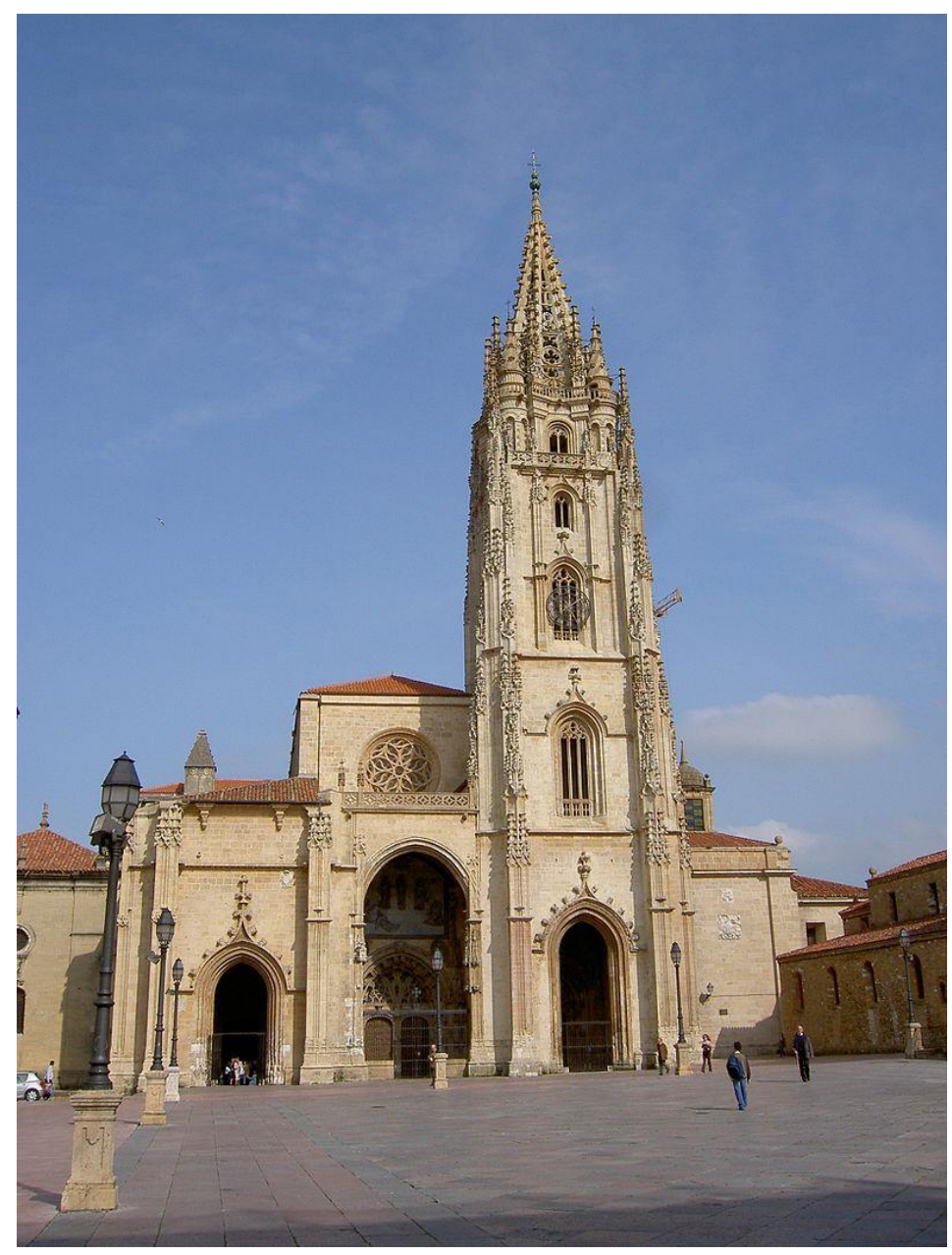

Fig. 3: Catedral de Oviedo.

Asimismo, se formó en composición con el entonces Maestro de capilla de la catedral ovetense, Joaquín Lázaro ${ }^{16}$. Garay abandonó la catedral de Oviedo en febrero de 1785, es decir, seis años después de haber ingresado, con el objetivo de residir en Madrid y ampliar sus conocimientos de órgano en la capital de España.

\footnotetext{
15 Sobre este organista, véanse Arana Martija, 1976: 129-130, y González Pérez, 1980 y 1981.

16 Sobre Joaquín Lázaro, consúltense Casares, 1980; Quintanal, 1983; y Arias del Valle, 1990.
} 


\section{PaUlino CAPDEPón Verdú}

\subsection{GARAY EN MADRID ${ }^{17}$}

Arias del Valle plantea la posibilidad de que Garay ingresara en el monasterio de la Encarnación en Madrid ya que en 1786 su antiguo maestro de órgano en la Catedral Oviedo, Juan Andrés Lombide, fue primer organista de dicho monasterio madrileño. Por su parte, Pedro Jiménez afirma en su estudio sobre la música en la catedral de Jaén que Garay perfeccionó sus estudios de órgano con el maestro y organista de la Real Capilla, José Lidón. Además compatibiliza sus estudios con el puesto de Maestro de música de los niños seminaristas en el convento de los Jerónimos del Retiro de Madrid (Jiménez, 1991: 114).

El certificado que expidió el prior del monasterio de San Jerónimo de Madrid, fray Antonio de Montemayor, con motivo de la oposición de Garay al magisterio de Jaén, resulta relevante para conocer las actividades y estancia de Garay en dicho monasterio:

Fray Antonio de Montemayor, prior del real monasterio de San Jerónimo del Retiro de esta Corte de Madrid. Certifico, en la debida forma, que habiendo precedido los correspondientes informes de personas timoratas, que conocían de vista y trato continuado a don Ramón Garay, profesor y compositor en la facultad de la música, fue éste recibido en dicho monasterio para la enseñanza en ella y educación en las buenas costumbres de los niños, que están destinados para la asistencia de su coro y oficios divinos; habiéndose experimentado en el discurso de más de un año, que ha ejercitado este encargo, los particulares adelantamientos de aquéllos, en uno y en otro; procurando instruirles con el ejemplo, que verdaderamente ha dado a todos en el recogimiento, acciones, palabras, frecuencia de sacramentos y arreglada conducta en todas sus operaciones; y en cuanto a las producciones de su facultad, que repetidas veces se han cantado en esta iglesia, ha merecido distinguido mérito entre los facultativos, y agrado en los demás oyentes, que es cuanto puedo decir; y para que en cualquier parte obre los efectos que haya lugar, doy la presente, que rmo. Madrid y noviembre, 3 de 1786. Fray Antonio de Montemayor, prior de san Jerónimo (ACJ, Expediente de oposiciones al magisterio de capilla (1784-1787): Certificado de fray Antonio de Montemayor, 3 de noviembre de 1786) ${ }^{18}$.

${ }^{17}$ En torno al Madrid de aquella época, véanse Ringrose, 1985; Andioc, 1987; Fernández García, 1993 y 2008; PáezCamino, 1994; Juliá, Segura y Ringrose, 1998; Cepeda Adán, 2001.

18 Citado en Jiménez, 2011a: 540. 


\section{LA TRANSICIÓN AL SIGLO XIX EN LA CATEDRAL DE JAÉN: EL MAESTRO DE CAPILLA RAMÓN GARAY (1761-1823)}

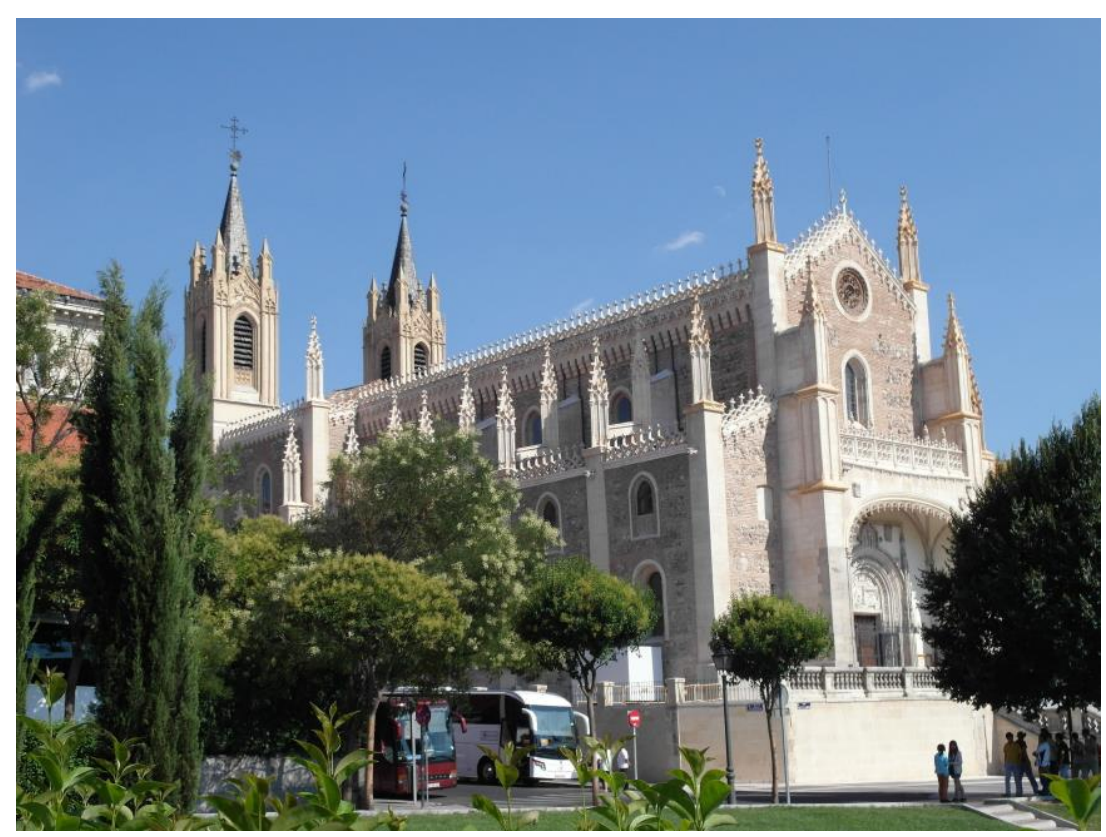

Fig. 4: Monasterio de San Jerónimo el Real de Madrid.

El ambiente musical de Madrid permitió a Garay conocer las novedades del sinfonismo clásico centroeuropeo ya que las obras de Haydn ${ }^{19}$ y en menor medida de Mozart ${ }^{20}$ eran interpretadas tanto en la corte madrileña como en los salones privados de las grandes familias nobiliarias de Madrid: de hecho, José Lidón, el maestro de Garay en Madrid, era el responsable de la orquesta de la condesa-duquesa de Benavente y en su repertorio se contaban las sinfonías de Joseph Haydn (Jiménez, 1987: 17). Tal oportunidad y experiencia fueron posiblemente decisivas para un joven Garay que estaba predestinado a desempeñar un papel de primer orden en la consolidación del géneros sinfónico español años después.

Es incontestable que Garay se prodigó durante la etapa de estudios en Madrid en calidad compositor, dándose a conocer y gozando del reconocimiento "de los más científicos maestros y profesores de esta corte", tal como lo certifica el informe que su maestro José Lidón redactó como apoyo a la aspiración del compositor avilesino al magisterio de la Catedral giennense:

\footnotetext{
19 Sobre la recepción de la música de Haydn en España, consúltense Solar-Quintes, 1947; Vilar, 1984; Alier, 1985; Díez, 2003; Aparisi, 2008; Montero, 2011 y 2011a; "Franz Joseph Haydn y el Clasicismo musical en España”, 2011. Número monográfico de Revista MAR. Música de Andalucia en la Red, $\mathrm{n}^{\mathrm{o}} 1$ (http://mar.ugr. es/static/MAR_Revista/*/1); Gosálvez Lara, 2009; Klauk, 2011; Garbayo, 2013; Ruiz Tarazona, 2018.

20 Por lo que se refiere a la recepción de la música de Mozart en España, véanse Alier, 1990; Radigales, 1998 y 2006 ; Wyn Jones, 2003; Capdepón, 2006, 2007, 2011, 2012; García Laborda y Arteaga, 2008; Capdepón y Pastor, 2016; Ruiz Tarazona, 2018.
} 


\section{PaUlino CAPDEPón Verdú}

Don José Lidón, organista de la Real Capilla de su Majestad, que Dios guarde, y Maestro del estilo italiano del Real Colegio de Música de esta corte, certifico cómo don Ramón Garay tiene acreditado su mérito completamente en la carrera de Maestro de capilla que profesa por las varias obras, así latinas como de romance, que se han cantado en diferentes funciones principales con general aplauso de los más científicos maestros y profesores de esta corte, habiendo hecho constar en dichas obras su posesión, así en la propiedad de su música característica de templo como en el ramo del buen gusto, circunstancias en las cuales se cifra la verdadera composición música. Asimismo, se halla adornado de las demás prendas apetecibles de buena índole, conducta, etc. Todo lo cual tiene bien acreditado y por tanto doy la presente para que pueda presentarla donde convenga, que así lo siento en esta de Madrid, a 9 de noviembre de 1786. José Lidón (ACJ, Expediente de oposiciones al magisterio de capilla (1784-1787): Certificado José Lidón, 9 de noviembre de $1786)^{21}$.

\subsection{MAESTRO DE CAPILLA DE LA CATEDRAL DE JAÉN}

La sustitución de Francisco Soler ${ }^{22}$, fallecido en 1784, por Ramón Garay al frente del magisterio giennense fue bastante polémica. En una primera tentativa tubo lugar un concurso de méritos en 1785 para suceder a Soler mediante informes sobre los conocimientos y calidad de las obras de los candidatos. A dicha oposición por informes, en la cual no llegó a participar Garay, se presentaron inicialmente once candidaturas procedentes de todo el país, a las que se sumaron posteriormente dos más. Los maestros encargados de elegir nuevo Maestro de capilla de la Catedral de Jaén fueron Antonio Rodríguez de Hita, Maestro de capilla de La Encarnación, Francisco Javier García Fajer, Maestro de la Catedral de La Seo de Zaragoza, y Sebastián Tomás, Maestro de capilla de la Catedral de Valladolid, Antonio Ripa, Maestro de capilla de la Catedral de Sevilla, y Francisco García Pacheco, Maestro de la Iglesia de la Soledad de Madrid (Jiménez, 2011a: 87ss). Finalmente fue Ramón Ferreñac el elegido, discípulo del propio informante García Fajer, pero renunció al puesto ya que entretanto había obtenido el cargo de organista de la Catedral de Zaragoza.

El segundo intento se produce en agosto de 1786 cuando se emiten edictos para proveer la plaza de maestro de capilla de Jaén. Una vez remitido el edicto a iglesias repartidas por toda España, como era usual en la época, se presentaron a la plaza Francisco de Paula González, quien ya había participado en el concurso de méritos antes mencionado, y Ramón Garay, el cual envió desde Madrid el siguiente informe, solicitando tomar parte en la oposición:

\footnotetext{
${ }^{21}$ Citado en Jiménez, 2011a: 540.

${ }^{22}$ En torno a la trayectoria de Francisco Soler en la Catedral de Jaén al frente del magisterio musical, véase Capdepón 2011a.
} 


\section{LA TRANSICIÓN AL SIGLO XIX EN LA CATEDRAL DE JAÉN: EL MAESTRO DE CAPILLA RAMÓN GARAY (1761-1823)}

Ilustrísimo Señor. Don Ramón Garay, natural de la villa de Avilés, Principado de Asturias, de edad veinticinco años y residente en esta corte, con el mayor respeto hace presente a Vuestra Señoría Ilustrísima: como siendo su carrera la de Maestro de capilla, cuya escuela ha practicado bajo la dirección de don José Lidón, Maestro del Colegio del Rey y organista de su Real Capilla y habiéndose hecho cargo del edicto fijado para la oposición al magisterio de esa santa Iglesia y hallarse proporcionado en todas las circunstancias que en él se expresan; en esta atención, a Vuestra Señoría Ilustrísima suplica se digne admitirle al concurso a fin de hacer presente su ciencia, favor que espera recibir de la justificación de Vuestra Señoría Ilustrísima. Madrid, 12 de septiembre de 1786. Besa la mano de Vuestra Señoría Ilustrísima su 232 más rendido servidor. Ramón Garay (ACJ, Expediente de oposiciones al magisterio de capilla (1784-1787): Solicitud de Ramón Garay, 12 de septiembre de 1786) ${ }^{23}$.

En esta segunda convocatoria, sólo actuó un juez censor: Jaime Balius El comienzo de las oposiciones se fija el día 30 de octubre de 1786, invitándose a los canónigos de la catedral de Baeza para que asistan a éstas, seguramente debido a las estrechas relaciones entre las dos catedrales (ACJ, Actas capitulares, vol. de 1786, Acta de 21 de octubre de 1786, $\mathrm{s} / \mathrm{f}$.). Un día antes del comienzo de las oposiciones, Jaime Balius se pone en contacto con el Cabildo para acordar los términos de la oposición y además se ve la necesidad de que los opositores conozcan la dotación vocal-instrumental de la capilla musical giennense, para de esta forma adaptar mejor sus obras a las disponibilidades de dicha capilla (ACJ, Actas capitulares, vol. de 1786, Acta de 29 de octubre de 1786, s/f.). Los ejercicios de la oposición se concentran en la composición de un villancico y varios salmos (ACJ, Actas capitulares, vol. de 1786, Acta de 31 de octubre de 1786, s/f.). A comienzos de noviembre de aquel año, el maestro de Úbeda presenta su renuncia a continuar optando a la plaza de maestro de la Catedral de Jaén a causa de la dureza en el segundo de los ejercicios -la composición de varios salmos- y no haber sido capaz de finalizarlos en el tiempo asignado (ACJ, Actas capitulares, vol. de 1786, Acta de 7 de noviembre de 1786, s/f.).

Para leer la censura escrita por Balius se fija el día diez de noviembre de 1786 (ACJ, Actas capitulares, vol. de 1786, Acta de 10 de noviembre de 1786, s/f.). Ramón Garay hace acto de presencia por primera vez en esta oposición para hacer constar al Cabildo giennense su protesta por el juicio negativo que Balius había vertido sobre sus obras ((ACJ, Actas capitulares, vol. de 1786, Acta de 10 de noviembre de 1786, s/f.). Sin embargo, al poco tiempo, el compositor asturiano se vio obligado a rebajar el tono de sus protestas, si bien adjuntó otras certificaciones sobre su preparación musical (ACJ, Actas capitulares, vol. de 1787, Acta de 5 de febrero de 1787, s/f.). El 13 de febrero de 1787 se celebra una reunión para debatir sobre la carta de protesta de Ramón Garay y se acuerda que se le plantee tal cuestión al Obispo de Jaén, Agustín Rubín de Ceballos. Al poco tiempo se recibe la respuesta del citado Obispo, quien entregará el examen de Garay así como la censura de Garay a los maestros de la Santa Primada de Toledo y la Real Capilla de Madrid (ACJ, Actas capitulares, vol. de 1787, Acta de 3 de marzo de 1787, s/f.).

${ }^{23}$ Citado en Jiménez, 2011a: 534-535. 


\section{PaUlino CAPDEPón Verdú}

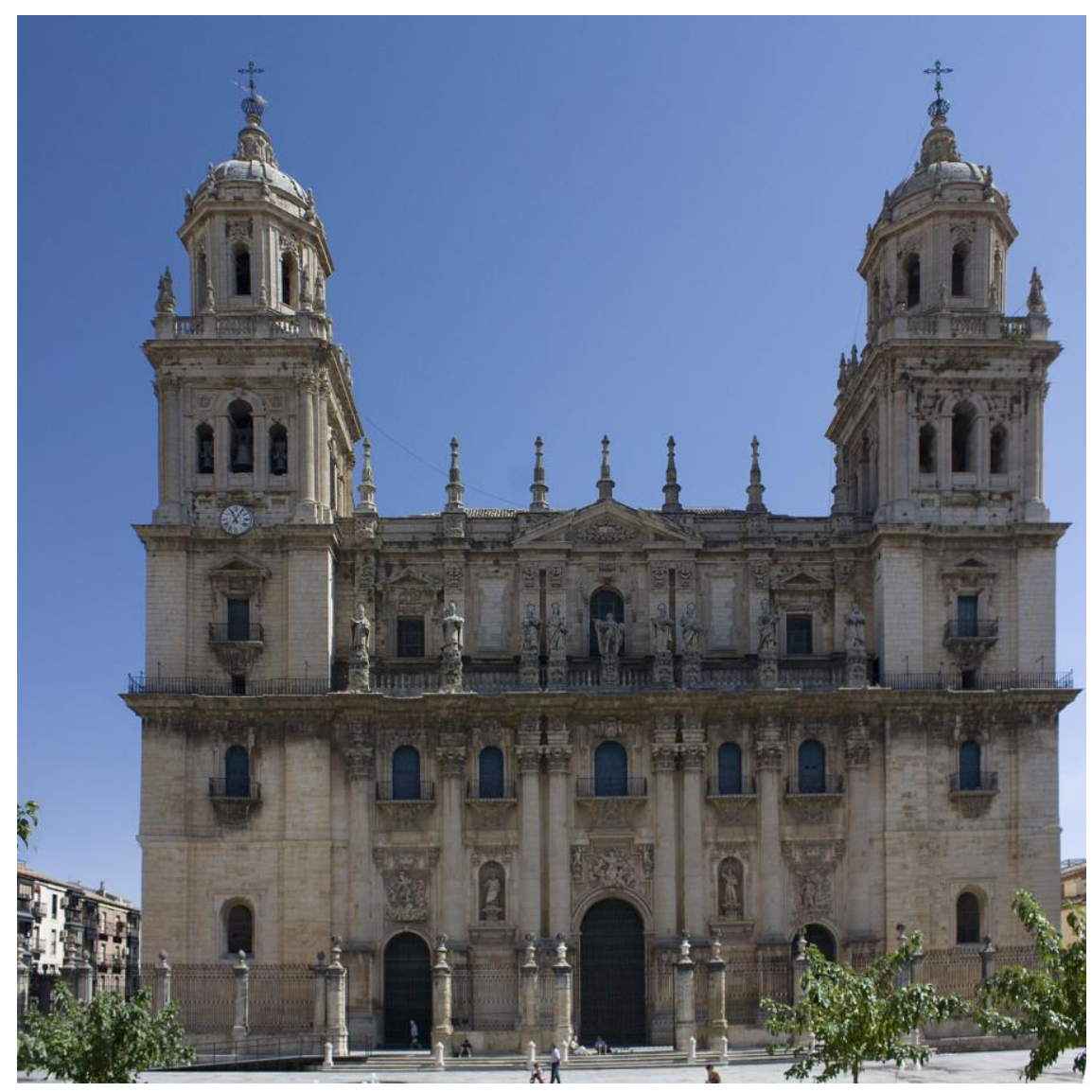

Fig. 5: Catedral de Jaén.

La polémica en torno a la impugnación por parte de Ramón Garay del dictamen de Balius se salda en mayo de 1787 a favor del primero cuando el Obispo de Jaén, Agustín Rubín de Ceballos, dictamina, a la vista de las opiniones de Antonio Ugena, (maestro de la Real Capilla de Madrid), Francisco Juncá (maestro de la Catedral de Toledo), y Antonio Ripa (maestro de la catedral de Sevilla, que tenía "el gusto de cortar el asunto con seguridad de su conciencia, certificando que desempeñará cada día mejor el ministerio de capilla dicho don Ramón Garay, y que en el día es suficiente para la obtención de este empleo" (ACJ, Actas capitulares, vol. de 1787, Acta de 11 de mayo de 1787). El 22 de mayo se solicita a Garay su genealogía para comenzar con el proceso de admisión y limpieza de sangre (ACJ, Actas capitulares, vol. de 1787, Acta de 22 de mayo de 1787, s/f.). A los tres días, el maestro asturiano presenta su genealogía y su partida de bautismo, pero al mismo tiempo ruega al Cabildo giennense que le autorice a regir la capilla catedralicia, a lo que se le contesta de forma afirmativa (ACJ, Actas capitulares, vol. de 1787, Acta de 25 de mayo de 1787 , s/f.). Por fin, en noviembre de 1787 se analizan las pruebas de limpieza de sangre y se le concede la posesión de su cargo, primero en el Cabildo y después en el Coro, poniendo final a un proceso que había durado alrededor de un año (ACJ, Actas capitulares, vol. de 1787, Acta de 7 de noviembre de 1787, s/f.). 


\section{LA TRANSICIÓN AL SIGLO XIX EN LA CATEDRAL DE JAÉN: EL MAESTRO DE CAPILLA RAMÓN GARAY (1761-1823)}

Puede dividirse la estancia de Garay en Jaén en tres fases: primera etapa (1787-1800), segunda etapa (1801-1816), y tercera y última etapa (1816-1823). Por lo que respecta a la primera, destacan, entre otros hechos, la inauguración de un nuevo órgano en junio de 1788 (ACJ, Actas capitulares, vol. de 1788, Acta de 25 de junio de 1788, s/f.). Es asimismo frecuente que a Garay el Cabildo se le solicite información periódica sobre el grado de aprovechamiento y dedicación a los estudios musicales de los seises así como de sus aptitudes para el órgano (ACJ, Actas capitulares, vol. de 1788, Acta de 29 de agosto de 1788, $\mathrm{s} / \mathrm{f}$.). Otra de las cuestiones fundamentales que se plantea durante esta primera fase del magisterio de Ramón Garay estriba en la progresiva sustitución de los villancicos: a lo largo del siglo XVIII las reacciones contra de la introducción del villancico en las iglesias se habían acentuado de tal manera que a finales del mismo siglo se decretaría la prohibición de interpretar villancicos en algunas catedrales e iglesias por parte de los diversos Cabildos y Jaén no constituye una excepción a esta tendencia. Ciertos teóricos españoles de aquel siglo insistían en que la música debía convertirse en un medio de devoción y recogimiento religiosos, y no un motivo para el placer auditivo. Así, en diciembre de 1788 se trata en una reunión capitular de unos responsorios de Navidad y Reyes de José de Nebra, antiguo Organista y Vicemaestro de la Real Capilla de Madrid, que el Obispo había obtenido en la Catedral de Cuenca, el cual proponía que se interpretaran en lugar de los villancicos

que hasta ahora se han acostumbrado, como se va introduciendo en las Iglesias Catedrales más serias del reino; y que habiéndolos hecho reconocer del Maestro de capilla de esta santa Iglesia para que viese si podían ejecutarse por esta capilla de música, le había informado, después de haber hecho un grande elogio de la obra, que por estar compuesta con dos tiples de primer Coro, y no haber al presente en esta capilla ninguno, no podría ejecutarse sin mucho deslucimiento; en vista de lo cual podría el Cabildo determinar lo que tuviera por conveniente y mandar, si gustaba, que se archivasen dichos responsorios hasta que hubiese proporción de cantarlos como lo deseaba Su Ilustrísima (ACJ, Actas capitulares, vol. de 1788, Acta de 5 de diciembre de 1788, s/f.).

Finalmente, el ofrecimiento del Obispo fue aceptado por parte del Cabildo de la Catedral de Jaén. Por otra parte, una de las cuestiones más polémicas en las relaciones del Cabildo con su capilla de música se centra en las actuaciones extracatedralicias de la mencionada capilla. El interés de los músicos eclesiásticos en la España del siglo XVIII por intervenir en las festividades religiosas de otras iglesias o en las de carácter profano se debía a que constituye una de las pocas vías para aumentar las escasas retribuciones que en ocasiones recibían por parte de los Cabildos: Jaén no va a ser una excepción a esta práctica habitual y en especial son continuas las peticiones de autorización para participar en otros actos fuera de la catedral. No siempre eran concedidas tales peticiones o son concedidas parcialmente, como ocurre en noviembre de 1790, cuando el Cabildo giennense prohíbe que los cantores o instrumentistas de la capilla catedralicia salgan fuera de la ciudad a la esta de algún pueblo. En caso de que no se acate por parte de los músicos las decisiones negativas del Cabildo al respecto, puede llegarse a la multa económica o a la expulsión 


\section{PaUlino CAPDEPón Verdú}

(ACJ, Actas capitulares, vol. de 1790, Acta de 4 de noviembre de 1790, s/f.).

Un momento crucial en la carrera de Garay tuvo lugar a comienzos de 1792, cuando el Cabildo de Jaén nombró a Ramón Garay como Rector del Colegio de seises, para lo cual se dictamina buscar un emplazamiento adecuado (ACJ, Actas capitulares, vol. de 1792, Acta de 27 de enero de 1792, s/f.). Además de informar periódicamente sobre la evolución de los seis en materia musical, otra de las obligaciones de Garay en su calidad de Maestro de capilla es la emisión de informes sobre los nuevos aspirantes a formar parte de la capilla musical. De la misma manera, los propios músicos de plantilla pueden solicitar las plazas que han quedado vacantes por fallecimiento o por dimisión, como es el caso del cantor de la capilla Francisco Lozano, quien arguye en su favor, entre otras razones, la antigüedad en su pertenencia a la capilla musical (ACJ, Documentos de Secretaría: Memorial de Francisco Lozano, 24 de agosto de 1792) ${ }^{24}$; otra de las causas por las que los propios miembros de la capilla musical giennense se dirigen al Cabildo (especialmente por parte de aquellos miembros que cuentan con una dilatada experiencia, como fue el caso del cantor Francisco Lozano), viene determinada por la solicitud de provisión de una plaza concreta, con el fin último de obtener una mejora sustancial en la percepción de sus honorarios (ACJ, Documentos de Secretaría: Memorial de Francisco Lozano, 25 de agosto de 1792)25.

En otro orden de cosas, no faltan las recriminaciones del Cabildo de Jaén hacia su Maestro de capilla: así, a finales de 1796 el Cabildo reprende a Garay por las actuaciones de la capilla ya que "a veces va muy pesada y varias funciones se alargan demasiado, otras parece que hay falta de voces por no concurrir todos los músicos, y finalmente que en los maitines de la noche de navidad no se ha acabado de arreglar el tiempo de su duración, habiendo sucedido en muchos años que se acababan después de la una y media de la mañana". Por tal razón se acuerda que "el señor racionero Maestro de capilla disponga sus composiciones de música y la ejecución de ella de modo que no cause molestia, ni desmaye la devoción de los que la oyeren procurando en los maitines de Navidad ir de concierto con el sochantre que gobierna el coro para que nunca se acaben antes de las doce y cuarto, ni excedan notablemente de las doce y media, entendiendo que el o cio principal en todas las funciones le lleva el coro en cuanto se canta el facistol, y que nada se puede rebajar de este y de la pausa y solemnidad con que se han de cantar los salmos, antífonas, versos y lecciones" (ACJ, Actas capitulares, vol. de 1796, Acta de 1 de diciembre de 1796, s/f.). El Cabildo volvió a llamar la atención a Garay por las intervenciones de la capilla pues hay obras "que se hacen muy pesadas", advirtiéndose además que en vez de villancicos se canten responsorios y motetes, siguiendo la tendencia preponderante en la mayoría de las catedrales españolas a finales del siglo XVIII, en el sentido de sustituir las obras religiosas en español por otras en latín (ACJ, Actas capitulares, vol. de 1798, Acta de 1 de febrero de $1798, \mathrm{~s} / \mathrm{f}$.).

\footnotetext{
${ }^{24}$ Citado en Jiménez, 2010: 307.

25 Ibidem, 308.
} 


\section{LA TRANSICIÓN AL SIGLO XIX EN LA CATEDRAL DE JAÉN: EL MAESTRO DE CAPILLA RAMÓN GARAY (1761-1823)}

En el curso de esta primera etapa, el Organista de la Catedral, Mauricio Soler, falleció en febrero de 1798 (ACJ, Actas capitulares, vol. de 1798, Acta de 16 de febrero de 1798, s/f.), lo cual propicia que se inicien varios movimientos en torno a su sucesión: 1 . El músico de la capilla, Pascual Luque, pide autorización para hacerse cargo del órgano provisionalmente hasta que se provea la plaza en un nuevo organista titular en lugar de Soler, petición que es aceptada inmediatamente (ACJ, Actas capitulares, vol. de 1798, Acta de 20 de febrero de 1798, s/f.). 2. Ramón Garay se dirigió al organista titular de la Colegiata de Antequera, a la sazón el burgalés Juan López ${ }^{26}$, para ofrecerle opositar al cargo, respondiendo éste que sólo aceptaría bajo ciertas condiciones económicas (ACJ, Documentos de Secretaría: Carta de Juan López, 24 de febrero de 1798) ${ }^{27}$. 3. Un organista de la corte, Alfonso Lidón, se interesa igualmente por ocupar la plaza dejada vacante por Mauricio Soler por hallarse "en la su ciencia necesaria en esta carrera"; el Cabildo debatió la oferta de Lidón y decide que se informe de su habilidad y buena conducta (ACJ, Actas capitulares, vol. de 1798, Acta de 8 de mayo de 1798, s/f.). 4. De nuevo el pasado en Madrid hace acto de aparición en la vida de Garay: se trata de Joaquín Asiaín, antiguo compañero y organista del monasterio de San Jerónimo en Madrid, donde, Garay había ejercido el cargo de maestro de música- Asiaín recomienda a un discípulo suyo, llamado Santiago Aguirre, en un informe dirigido a Fernando de la Cueva (ACJ, Documentos de Secretaría: Carta de Joaquín Asiaín, 16 de mayo de $1798)^{28}$. 5. Un nuevo aspirante se dirige al Cabildo para interesarse por el puesto e informar de su buena conducta: se trata de Gregorio Vallejo, capellán de la Colegial de Lorca (ACJ, Documentos de Secretaría: Carta de Gregorio Vallejo, 17 de mayo de 1798)29. Fue Joaquín Asiaín, pese a recomendar a su discípulo Santiago Aguirre, el encargado de dirimir la organistía giennense, tal como se desprende de un detallado informe: entre otros aspectos afirma Asiaín que de los pretendientes a la organistía sólo "exceden" el propio Santiago Aguirre y Juan López. Finalmente es Santiago Aguirre el elegido como primer organista y un salario de 600 ducados, adoptándose al mismo tiempo otras dos decisiones: la jubilación de Jacinto Núñez, segundo organista, y el nombramiento como de Pascual Luque como segundo organista (ACJ, Actas capitulares, vol. de 1798, Acta de 25 de mayo de 1798, s/f.).

\footnotetext{
${ }^{26}$ Se trata del Organista que ejercido tal cargo en la Colegiata de Santa María la Mayor de Talavera de la Reina, quien había abandonado este puesto para convertirse en el nuevo Organista de la Colegiata de Antequera, si bien acabó regresando a Talavera para trabajar como organista segundo; (dado que había contraído nupcias, no podía aspirar a recuperar su antiguo estatus de primer Organista: al respecto, véase Capdepón, 2012a. Sobre la estancia de López en Antequera, consúltense Llordén, 1976-1977, 1978-1980.

27 Citado en Jiménez, 2010: 335-336.

${ }^{28}$ Citado en Jiménez, 2010: 339-340.

${ }^{29}$ Citado en Jiménez, 2010: 340-341.
} 


\section{PAUlino CAPDEPón Verdú}

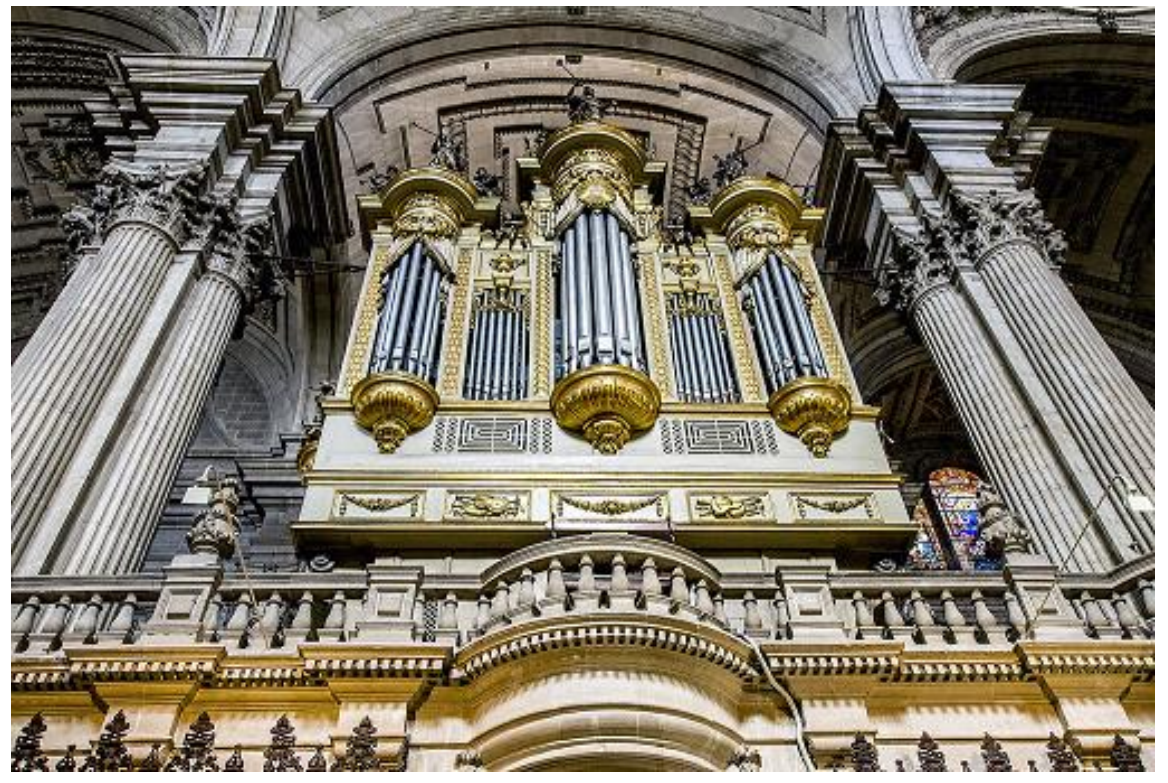

Fig. 6: Órgano de la Catedral de Jaén.

En cuanto a la segunda etapa de Garay en Jaén (1801-1816), los principales hechos de su magisterio son los siguientes. De nuevo surgieron diferencias entre Ramón Garay y el Cabildo en cuanto a la extensión y contenido de la música compuesta por el maestro asturiano, lo cual anuncia la decadencia que sufrirá la capilla de música y la pérdida de influencia de la música en la vida litúrgica de la Catedral giennense, que se acentuará conforme avance el siglo, todo ello a pesar de los esfuerzos del cabildo para informarse en Madrid sobre posibles nuevos integrantes de la capilla (ACJ, Actas capitulares, vol. de 1801, Acta de 24 de noviembre de 1801, s/f.). En marzo de 1803 se emiten edictos de oposiciones para cubrir las plazas de Sochantre primero y segundo así como la de salmista: a tales oposiciones, celebradas en mayo de aquel año, se presentaron candidatos procedentes de Granada, Toledo, Santiago, Málaga, Jaén, Segovia, Valencia, Antequera, Salamanca y Guadix, lo cual indica la pujanza y el atractivo que había alcanzado la capilla musical giennense a comienzos del siglo XIX (ACJ, Actas capitulares, vol. de 1803, Acta de 31 de mayo de 1803, s/f.): finalmente fueron seleccionados Francisco Villuendas como Sochantre primero y Pedro Cárdenas y Juan Fernández Poveda como Sochantres segundos para que asistan a Villuendas y se turnen por semanas en la dirección del coro (ACJ, Actas capitulares, vol. de 1803, Acta de 1 de junio de 1803, s/f.).

En 1803 vuelve a tratarse la cuestión del deficiente estado de la capilla de música, aludiendo Garay a "la falta tan grande que hay de instrumentos de aire, que tan indispensables son para ejecutar las obras de más lucimiento en los días más solemnes, y también para los ofertorios, claustraciones, facistol y cantollano" (ACJ, Documentos de Secretaría: Memorial de Ramón Garay, 18 de febrero de 1803) ${ }^{30}$. El Cabildo intenta hallar una solución, como puede comprobarse en el siguiente acuerdo capitular:

30 Citado en Jiménez, 2010: 363. 


\section{LA TRANSICIÓN AL SIGLO XIX EN LA CATEDRAL DE JAÉN: EL MAESTRO DE CAPILLA RAMÓN GARAY (1761-1823)}

En este día dichos señores, teniendo en consideración el deplorable estado en que se halla la Capilla de música de esta santa Iglesia y que las funciones clásicas de ella no pueden celebrarse con la solemnidad y Majestad que corresponde, acordaron que para ocurrir a su oportuno remedio con el conocimiento debido se sirva el señor superintendente de fábrica formar un estado de los salarios en granos y maravedíes que perciben los músicos y el que tienen las rentas de dicha fábrica, y se pase a los señores doctoral y penitenciario para que en su vista y de las demás noticias que hayan recibido sobre este asunto, evacúen con la brevedad que les sea posible la comisión que tienen para el arreglo (ACJ, Actas capitulares, vol. de 1803, Acta de 14 de octubre de 1803, s/f.).

$\mathrm{Al}$ año siguiente se revela de nuevo la "deplorable" situación de la capilla de música. Garay expone al Cabildo que por "falta de voces e instrumentistas no pueden celebrarse las funciones en las festividades solemnes": en concreto, Garay afirma que son necesarios "un contralto, un bajete o tenor, un violinista y un músico que toque oboe, flauta y algún instrumento que aunque no sean de los más sobresalientes puede quedar servida la capilla dándoles unos salarios moderados". Hasta tal punto llegan las deficiencias que el propio Maestro dice que de los 61 responsorios que ha compuesto hasta la fecha, sólo puede interpretar uno, por estar dotado a una sola voz; jẹ pesar de ello y de las dificultades, el Cabildo manifiesta su satisfacción con la labor de su Maestro de capilla y le autoriza para que elija los músicos que son necesarios para el buen funcionamiento de la capilla musical (ACJ, Actas capitulares, vol. de 1804, Acta de 24 de octubre de 1804, s/f.). Un año después, en 1805 se cumplen las promesas del Cabildo y se contrata a parte de los músicos solicitados por Garay, después de haber elaborado éste un extenso informe previo: se trata del contralto conquense Antonio Sanz, del tenor bajete aragonés Miguel Gomara, del violinista sevillano Fructuoso Gómez y del bajonista de la Real Capilla de Granada, Francisco Navarro (ACJ, Actas capitulares, vol. de 1805, Acta de 12 de febrero de 1805, s/f.). Con respecto a las quejas de Garay sobre el emplazamiento de la capilla musical, el Cabildo acuerda situarla en un lugar más "proporcionado", donde se evite "la mucha concurrencia de gentes estimulados de la curiosidad y poca devoción, como se experimenta ahora en las puertas del coro todos los días que asiste la capilla" (ACJ, Actas capitulares, vol. de 1805, Acta de 2 de mayo de 1805 , s/f.).

La responsabilidad de dirigir el Colegio de San Eufrasio, cargo para el que había sido nombrado en 1792, como ya comprobamos con anterioridad, y la enseñanza musical de los seises que allí vivían, no dejan de constituir un quebradero de cabeza para Ramón Garay. Así, el octubre de 1805 el Cabildo decide que el arcediano de Baeza disponga que 


\section{PaUlino CAPDEPón Verdú}

se observen con la mayor exactitud las constituciones aprobadas que se dictaron para el gobierno del citado Colegio, las obligaciones del señor Maestro de capilla como tal y como Rector de él, las de los músicos de su voz e instrumentistas en orden a dar lecciones a los seises, y a resultas de todo mandará que a éstos se les instruya tanto en la música como en el canto e instrumentos, a proporción de su edad, aplicación y disposiciones para que de este modo puedan ser útiles al servicio de la Iglesia (ACJ, Actas Capitulares, vol. de 1805, Acta de 26 de octubre de 1805 , s/f.)

$\mathrm{Al}$ poco tiempo de recibir este aviso, Garay remite un memorial al Cabildo en el que expone "los accidentes que padece y su quebrantada salud no le permiten continuar con el Rectorado del Colegio de seises”. El Cabildo acuerda relevar a Ramón Garay del puesto de Rector del Colegio de seises (ACJ, Actas capitulares, vol. de 1805, Acta de 20 de diciembre de 1805, s/f.): sin embargo, dicha renuncia no se lleva a efecto, pues no se había nombrado hasta 1807 sucesor, razón por la que Garay se ve en la obligación de recordar de nuevo tal cuestión a causa de "sus habituales achaques y el notorio impedimento de su falta de voz y ronquera". Al final el Cabildo sólo le libera de la función de la enseñanza musical de los seises, excepto de la composición, pero mantiene a Garay en el cargo de Rector del Colegio de seises, sin salario (ACJ, Actas capitulares, vol. de 1807, Acta de 9 de junio de 1807, s/f.).

Las críticas a Garay por la forma de dirigir la capilla de música vuelven a manifestarse de nuevo a finales de 1808 cuando el Cabildo le advierte que

no se lleve con tanta precipitación el coro como se nota en algunos días y que se contengan los defectos de canto llano que se advierten en algunos de los que lo rigen y que los sochantres y salmistas se arreglen al rito del día haciendo la debida distinción entre los de primera clase, segunda y doble, y también la de semidoble (ACJ, Actas capitulares, vol. de 1808, Acta de 1 de diciembre de 1808, s/f.).

Un momento culminante en la vida de la ciudad tuvo lugar en 1810 con motivo de la visita de los reyes a Jaén en 1810, el Cabildo llega al acuerdo de obsequiarle con una "iluminación el día o días de su estancia en esta dicha capital", así como celebrar una esta solemne con Te Deum, el día de San José; en la víspera habrá repique general desde las 8 o 9 de la noche "alternando con la música que estará en palacio, a cuyo n concurrirá a las siete y media, y el día de San José asistirá la música a las seis de la tarde al mismo palacio" (ACJ, Actas capitulares, vol. de 1810, Acta de 15 de marzo de 1810, s/f.). La importancia del canto del Te Deum para ensalzar los principales actos celebrativos se ve remarcada de nuevo cuando se interpreta para festejar la victoria de las tropas rusas, aliadas de España, frente al ejército francés (ACJ, Actas capitulares, vol. de 1813, Acta de 4 de marzo de 1813, fol. 40r) o por la victoria obtenida en Vitoria frente a los mismos enemigos (ACJ, Actas capitulares, vol. de 1813, Acta de 28 de junio de 1813, fol. 110r). 
LA TRANSICIÓN AL SIGLO XIX EN LA CATEDRAL DE JAÉN:

EL MAESTRO DE CAPILLA RAMÓN GARAY (1761-1823)

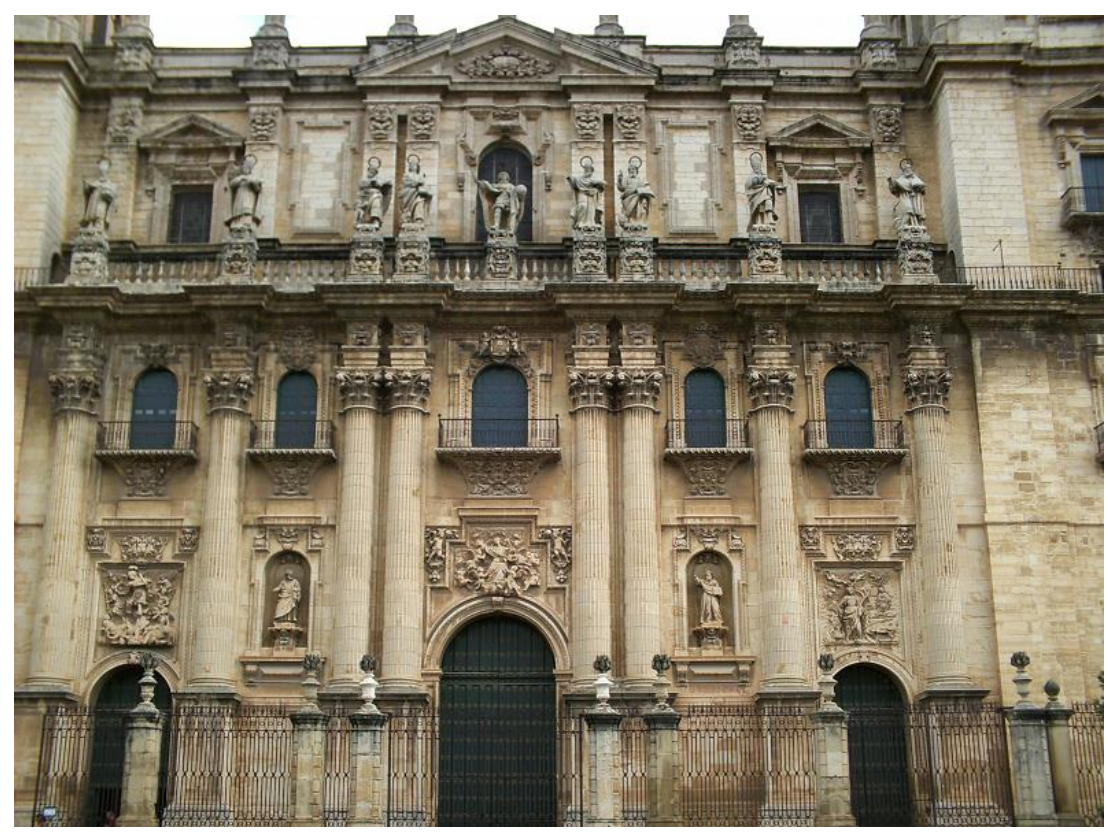

Fig. 7: Fachada de la Catedral de Jaén.

A partir de 1813 se multiplican las noticias sobre la decadencia de la capilla de música giennense y la difícil situación económica por la que atraviesan las rentas de la Catedral: así, se ordena a Ramón Garay que prepare las lamentaciones y el miserere de la Semana Santa de aquel año de forma que pueda valerse de los pocos músicos de que dispone (ACJ, Actas capitulares, vol. de 1813, Acta de 9 de marzo de 1813, fol. 43v). Al mes siguiente, y a causa de la escasez de buenas voces en la capilla, el Cabildo acepta que un tenor de Lucena, Dionisio López, se traslade a Jaén para cantar las lamentaciones de la Semana Santa pero al mismo tiempo solicita que el costo de esta contratación temporal sea el menor posible. La decadencia a la que nos referimos también afecta al Colegio de seises, como se denota en un memorial del Maestro dirigido al Cabildo, en el que llega a exponer que se halla en "estado de indigencia" debido a la disminución de las rentas correspondientes a su cargo de maestro y por no recibir salario alguno por su cargo de rector del mencionado Colegio (ACJ, Actas capitulares, vol. de 1814, Acta de 18 de enero de 1814, fol. 13v-14r). El Cabildo reacciona ante la lamentable situación de la capilla y sus carencias de personal aceptando que se contraten a los músicos indispensables para que las celebraciones de Semana Santa se celebren "con la decencia debida" (ACJ, Actas capitulares, vol. de 1814, Acta de 22 de marzo de 1814, fol. 71v). Para intentar remediar la escasez de miembros de la capilla y tras la pertinentes consultas con Ramón Garay, el arcediano de Baeza presenta en enero de 1815 un informe a comienzos de 1815 sobre las necesarias contrataciones de músicos para cubrir las vacantes: concretamente tres violinistas y un flautista-clarinetista (ACJ, Actas capitulares, vol. de 1815, Acta de 10 de enero de 1815, fol. 5v).

El prestigio musical alcanzado por Garay posibilitó que fuera invitado a dirigir la orquesta real en la corte madrileña de Fernando VII en torno a 1815 (Muñoz y Garnica, 1857: 146). Con ocasión de su estancia en Madrid, el compositor asturiano tuvo la 


\section{PAULINO CAPDEPón Verdú}

oportunidad de mostrar al monarca una obra dedicada a su persona: se trata de la primera versión del Oratorio al Santísimo que había compuesto en Jaén. Agradecido, el monarca ordenó copiar el oratorio con caligrafía lujosa a varios colores, privilegio reservado a las obras de gran importancia. Gracias a ello, se conserva en el actual Archivo General de Palacio una copia del mencionado oratorio, única obra de Garay conservada en dicho archivo real que además muestra una ampliación de la dotación instrumental con respecto a la versión original giennense ${ }^{31}$.

La tercera y última etapa final (1816-1823) de Garay al frente del magisterio giennense está marcada por la grave crisis por la que estaba atravesando la capilla musical desde años atrás: en este sentido, escribe un nuevo capítulo con el demoledor informe que envía Garay al Cabildo sobre el paupérrimo estado de la mencionada capilla: aludiendo a las ausencias y abandonos de determinados miembros de la capilla, las medidas que solicita para enderezar tal situación se reducen a la contratación de un bajo de primer coro o «un tenor de cuerpo que pueda suplir esta cuerda», de un tenor y de un violonchelo. Incluso afirma que en aquel momento ni la trompa ni el segundo coro está cubierto (ACJ, Documentos de Secretaría: Memorial de Ramón Garay, 16 de marzo de 1816) ${ }^{32}$. Como consecuencia de todo ello, Garay comienza a llevar a cabo gestiones para la búsqueda de nuevos músicos que puedan paliar las graves carencias que viene padeciendo la capilla musical de la Catedral giennense desde año atrás, gestiones que pueden resumirse de la siguiente forma:

1. Examen del bajo y salmista Manuel Raya, procedente de la Iglesia de Baeza, el cual es admitido en abril de 1816 (ACJ, Actas capitulares, vol. de 1816, Acta de 23 de abril de 1816, fol. 76v) sin embargo, y sin que conozcamos las causas exactas, dimitió de su puesto a las dos semanas de haber tomado posesión de su plaza (ACJ, Actas capitulares, vol. de 1816, Acta de 7 de mayo de 1816, fol. 76v).

2. Emisión de un informe en junio de 1816, en el que da cuenta al Cabildo de las diligencias efectuadas para cubrir diferentes plazas. De dicho informe se deduce que el Cabildo le había solicitado que encontrase «un bajete, un tenor y un organista segundo con el agregado de violonchelo», tarea que había sido infructuosa por diversas razones, pero ante todo por la escasez de buenos profesionales: es por ello que Garay aconseja que se emitan edictos de convocatoria de las plazas (ACJ, Documentos de Secretaría: Informe de Ramón Garay, 20 de junio de 1816) ${ }^{33}$. Efectivamente, siguiendo el consejo de su Maestro de capilla, el Cabildo acuerda convocar las plazas de segundo organista y de voces para el coro (ACJ, Actas capitulares, vol. de 1816, Acta de 21 de junio de 1816, fol. 130v).

\footnotetext{
${ }^{31}$ La denominación de la obra es la siguiente: Oratorio al Santísimo a cuatro voces que las cantan Cristo, el tenor. Pecador, el alto. Ángel, el tiple. Lu₹bel, el bajo. Con violines, violas, clarinetes, flautas, fagot, trompas y acompañamiento. Compuesto por D. Ramón Garay, Prebendado y Maestro de Capilla de la Santa Iglesia Catedral de Jaén, quien lo dedica a Nuestro Augusto soberano el señor D. Fernando VII. Archivo General de Palacio, Leg. 1610, Cat. 1408. Véase AA. VV., 1993: 284.

32 Citado en Jiménez, 2010: 459-460.

33 Citado en Jiménez, 2010: 461-462.
} 


\section{LA TRANSICIÓN AL SIGLO XIX EN LA CATEDRAL DE JAÉN: EL MAESTRO DE CAPILLA RAMÓN GARAY (1761-1823)}

3. Admisión de Francisco Calvo como nuevo tenor de la capilla (ACJ, Actas capitulares, vol. de 1816, Acta de 19 de septiembre de 1816, fol. 242v-243r).

4. Readmisión de Pascual Luque como segundo organista (ACJ, Actas capitulares, vol. de 1816, Acta de 3 de diciembre de 1816, fol. 253r).

5. Admisión de José Morales en calidad de violinista, del cual Garay opina que "es un profesor de mérito y que posee su instrumento con unos principios sólidos y una buena escuela; tiene un tono brillante y buena a nación, ejecución clara y firme en el compás, y con un gusto y expresión nada común”. Tal es el aprecio que siente el Maestro de capilla de Jaén por Morales que "si el referido faltase, se desbarataba toda la orquesta", además de resultar indispensable para enseñar su instrumento a los seises (ACJ, Documentos de Secretaría: Informe de Ramón Garay, 9 de mayo de 1817)³4.

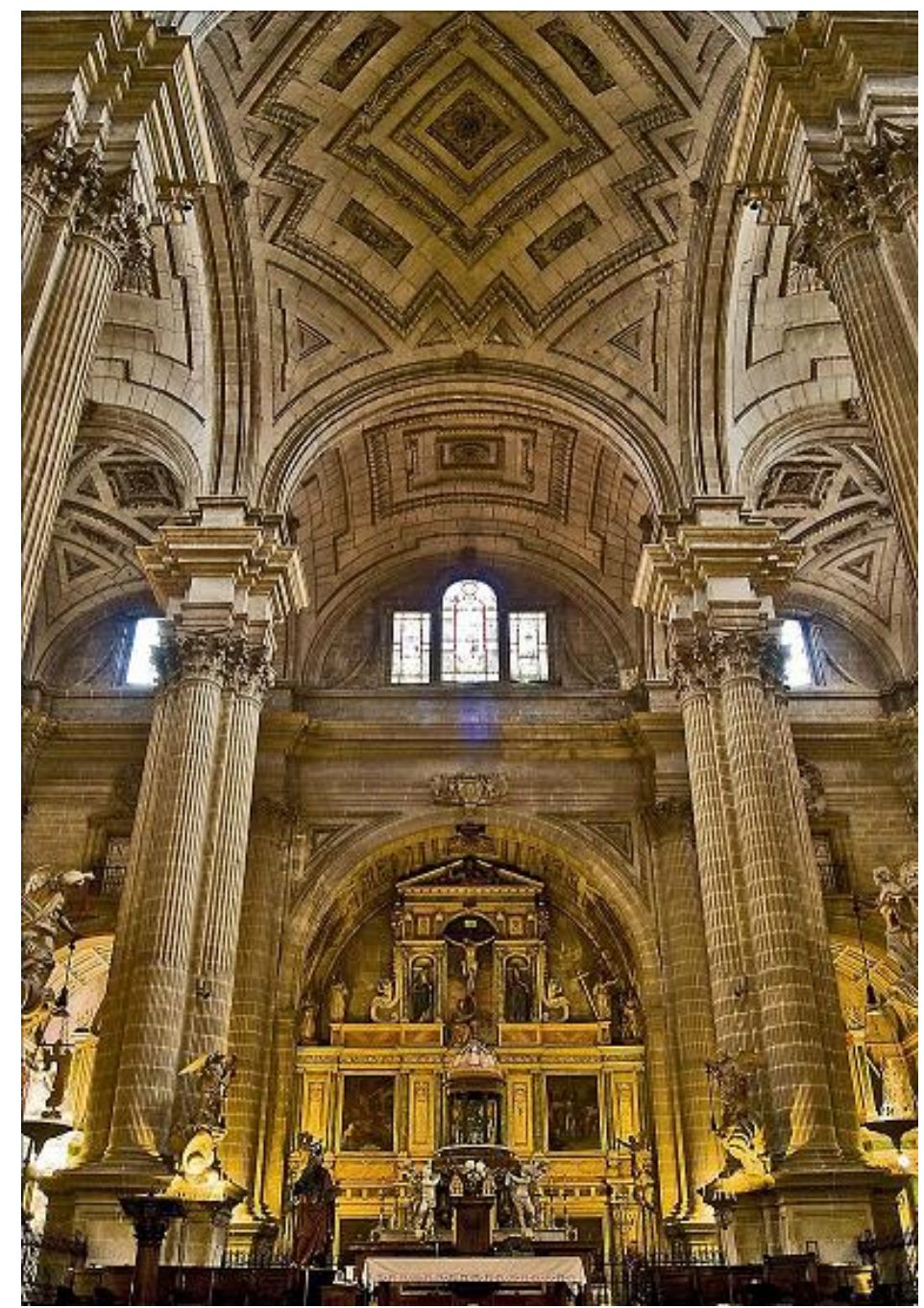

Fig. 8: Altar mayor de la Catedral de Jaén. 


\section{PAULINO CAPDEPón Verdú}

Por lo que se refiere al órgano, los dos organistas titulares de la Catedral preparan un informe en octubre de 1818, en el que hacen constar los graves problemas que padece el órgano, mencionando su "estado deplorable", por lo que solicitan se adopten las medidas oportunas para corregir este estado de cosas. Ante tal informe, el Cabildo acuerda emplear el órgano pequeño mientras se repara el órgano grande, misión que es encomendada a Lucas de la Redonda y otro organero, del que no se cita el nombre (ACJ, Actas capitulares, vol. de 1818, Acta de 17 de julio de 1818, fol. 177v-178r).

El permanente estado de decadencia de la capilla giennense se agudiza en septiembre de 1820 cuando el Cabildo decide rebajar en un tercio los salarios de los músicos y en una sexta parte los de los demás miembros al servicio del coro, altar y otros ministros de la Catedral (ACJ, Actas capitulares, vol. de 1820, Acta de 25 de septiembre de 1820, fol. 197r). La situación se agrava en agosto de 1821 cuando el Cabildo hace saber a los músicos y cantores que en las circunstancias actuales no puede asumir el pago de sus salarios, percibiéndolos sólo cuando los entregue la Junta diocesana: si ésta no puede abonarlos en su totalidad, estarán sometidos a los descuentos pertinentes; incluso se da carta de libertad a los músicos para que busquen nuevo acomodo en otra iglesia (ACJ, Actas capitulares, vol. de 1821-1822, Acta de 21 de agosto de 1821, fol. 141v). La reacción de los afectados por esta medida no se hace esperar y suplican al Cabildo que se les considere como a los restantes ministros del coro y redactan un memorial, denunciando su estado pues "quedan reducidos a la indigencia, pues carecen de todo arbitrio, mediante las presentes circunstancias" (ACJ, Documentos de Secretaría: Memorial de los músicos de la capilla, 28 de agosto de 1821) ${ }^{35}$. Las preocupaciones entre los músicos de la Catedral aumentan ante la incertidumbre que se está generando debido a la escasez de fondos que garanticen el abono de los salarios, ya que si "les faltan, vendrán a perecer de necesidad en un tiempo en que está cerrado cualquier otro arbitrio de que pudieran valerse", por lo que solicitan en septiembre de 1821 que se "arbitre modo de que se les continúe pagando sus mesadas como lo han experimentado hasta aquí y aun se hizo en las circunstancias aflictivas del Gobierno intruso" (ACJ, Documentos de Secretaría: Memorial de los miembros de la capilla musical, 21 de septiembre de 1821) ${ }^{36}$. Las protestas de los músicos de la capilla giennense por las rebajas de sus emolumentos continuaron sucediéndose también a lo largo de 1822 (ACJ, Actas capitulares, vol. de 1821-1822, Acta de 25 de enero de 1822, fol. 8v): ante el tono y volumen de las reclamaciones salariales, el Cabildo de Jaén decide abonar a sus músicos la mitad de su sueldo y las cinco sextas partes a los empleados del coro aduciendo la falta de fondos en metálico para pagar los salarios completos, tal como había sido decretado por el Obispo de la diócesis (ACJ, Actas capitulares, vol. de 1821-1822, Acta de 31 de enero de 1822, fol. 12r). Al poco tiempo, y con el fin de reestructurar las dimensiones de la capilla musical para adoptarlas a las nuevas condiciones económicas, se plantea proponer una nueva plantilla de la capilla con el fin de presentarla al Obispo para su posterior aprobación (ACJ, Actas capitulares, vol. de 1821-1822, Acta de 25 de febrero de 1822, fol. 24r.). Lo cierto es que la capilla de música está padeciendo en esta etapa final del maestro Garay una

\footnotetext{
35 Citado en Jiménez, 2010: 486-487.

36 Citado en Jiménez, 2010: 506.
} 


\section{LA TRANSICIÓN AL SIGLO XIX EN LA CATEDRAL DE JAÉN: EL MAESTRO DE CAPILLA RAMÓN GARAY (1761-1823)}

profunda crisis que se ha ido agudizando desde el n de la Guerra de la Independencia. A tal punto llega la decadencia que el mencionado maestro se ve obligado a solicitar la contratación de músicos fuera de la Catedral, y si ello no fuera viable, en vez de los misereres del Miércoles y Jueves Santo optaría por los misereres de Viernes Santo a fabordón (ACJ, Actas capitulares, vol. de 1821-1822, Acta de 23 de marzo de 1822, fol. 36v). Asimismo, cuando el Ayuntamiento de Jaén comunica al Cabildo que no está en condiciones de costear el solemne $\mathrm{O}$ cio de difuntos por su déficit económico, el Cabildo responde a su vez que se encuentra en la misma situación por falta de fondos para abonar a los miembros de su capilla sus correspondientes salarios (ACJ, Actas capitulares, vol. de 1821-1822, Acta de 1 de mayo de 1822, fol. 52r-v).

El estado de salud de Ramón Garay fue deteriorándose progresivamente durante los últimos años de su magisterio en Jaén. En agosto de 1822 Garay expone su deplorable estado de salud y solicita al Cabildo que se le conceda una prórroga a los cuatro meses iniciales de licencia de trabajo, algo a lo que acceden las autoridades catedralicias de la Catedral de Jaén: será la última licencia que disfrute el maestro asturiano. Finalmente, Ramón Garay falleció a las tres de la madrugada del 8 de enero de 1823 en la ciudad de Jaén, después de 36 años de servicio ininterrumpido en la capilla musical catedralicia de dicha ciudad:

En este día el señor Arcediano de Jaén, presidente de este Cabildo dio cuenta de que a las tres de la madrugada de este día había fallecido el señor racionero Maestro de capilla, don Ramón Garay, e inmediatamente puestos dichos señores en pie según costumbre, dijeron un responso por su alma. Enseguida se manifestó que el señor Arcediano de Baeza, que es uno de los albaceas de dicho difunto, había encargado se hiciese presente que el testimonio de la disposición testamentaria no se había podido sacar todavía por la premura del tiempo, pero que habiendo dejado dispuesto se le enterrase por el Cabildo como a los demás señores prebendados y dando treguas el cadáver a diferirlo para otro día había determinado se veri case en la tarde de hoy después de completas si el Cabildo lo tenía a bien, y oído por dichos señores acordaron se ejecute así y que el señor presidente hablando con los Maestros de ceremonias vea en que día deberá celebrarse la Misa (ACJ, Actas capitulares, vol. de 1823, Acta de 8 de enero de 1823, fol. 4v-5r).

\section{OBRA MUSICAL}

\subsection{REPERTORIO Y ESTILO}

La producción musical del compositor y maestro de capilla Ramón Garay muestra una gran diversidad y abarca un gran número de géneros musicales, algo inusual en un músico eclesiástico de la España de aquella época. En términos generales, su estilo musical, a falta aún del estudio pormenorizado de la obra vocal religiosa en latín, se encuadra dentro de la corriente estética de la Ilustración y del Clasicismo europeo, que tiene en Joseph Haydn su máximo exponente: es necesario citar la extraordinaria influencia que ejerció el 


\section{PaUlino CAPDEPón Verdú}

compositor austriaco en nuestro país, como lo demuestra la presencia de sus obras en los archivos civiles y religiosos de España. La etapa de aprendizaje con Joaquín Lázaro en Oviedo y con José Lidón en Madrid, dos de los compositores pioneros en la introducción del Clasicismo en nuestro país, fue decisiva para que Garay asumiera los elementos de dicho estilo.

Algo que asimismo es visible en su escritura instrumental, que en las obras vocales no se limita al mero acompañamiento de las voces sino que en diferentes momentos protagonizan el discurso musical, fruto de su propia y dilatada experiencia como sinfonista: no sólo llama la atención la importancia que concede a diferentes familias instrumentales (los aerófonos de madera dotan a sus obras de un característico timbre) sino que las voces intermedias como las violas adquieren carta de naturaleza y no se limitan a constituir un mero relleno.

\subsection{LA OBRA MUSICAL RELIGIOSA EN LATÍN Y ESPAÑOL}

Como consecuencia de sus obligaciones como maestro de la capilla giennense, Garay compuso un gran número de obras destinadas a la liturgia diaria, tanto en latín (misas, lamentaciones, responsorios, salmos, himnos, etc.) como en castellano (villancicos, pastorelas, tonadillas, etc.). Su técnica compositiva denota una notable inspiración y dominio de la escritura vocal, tanto la concebida para solistas como la coral (entradas y contestaciones en fugato, partes corales que se intercalan o dialogan, pasajes en tutti, etc.), dando lugar a melodías amplias, elaboradas y bien desarrolladas, cuidando en todo momento la expresividad y la perfecta correspondencia entre texto y música.

En su producción religiosa en español sobresale el único oratorio al Santísimo en castellano que compuso. Aunque no se conoce cuándo compuso exactamente dicho oratorio, probablemente surgió en la segunda mitad del siglo XVIII. En comparación a la primera versión de Jaén, en la versión conservada en el Archivo General de Palacio en Madrid, Garay cambia la orquestación primitiva ampliando las maderas gracias a los amplios recursos de la amplia orquesta de la Real Capilla de Palacio frente a la reducida plantilla que tenía a su disposición en la catedral de Jaén mientras que la dotación vocal es similar en ambas fuentes. El contenido del oratorio ofrece características moralizantes y está compuesto para cuatro personajes solistas: Cristo (tenor), Pecador (contralto), Ángel (tiple) y Luzbel (bajo). Por lo que se refiere a su estructura formal, se compone de introducción, cinco recitado-arias, dos villancicos con coplas y un final. Los recitados pertenecen a la modalidad de recitados accompagnato debido a la intervención de la sección de cuerda aunque en ocasiones están presentes también las trompas y el fagot. Por su parte, las arias se liberan de la exclusividad de la estructura tripartita del aria da capo, mostrando variadas fórmulas. La orquesta está formada por dos clarinetes, dos flautas, un fagot, dos trompas y sección de cuerda que presenta las violas divididas en primeras y segundas. Desde el punto de vista musical, el oratorio presenta una amplia paleta de recursos tanto vocales como instrumentales y muestra hasta qué punto la influencia de Joseph Haydn estaba presente en la música española de la segunda mitad del siglo XVIII y comienzos del XIX, si bien en opinión de Tomás Garrido, el oratorio de Garay busca en todo momento 


\section{LA TRANSICIÓN AL SIGLO XIX EN LA CATEDRAL DE JAÉN: \\ EL MAESTRO DE CAPILLA RAMÓN GARAY (1761-1823)}

encontrar una voz personal y original (Garrido, 2011) ${ }^{37}$.

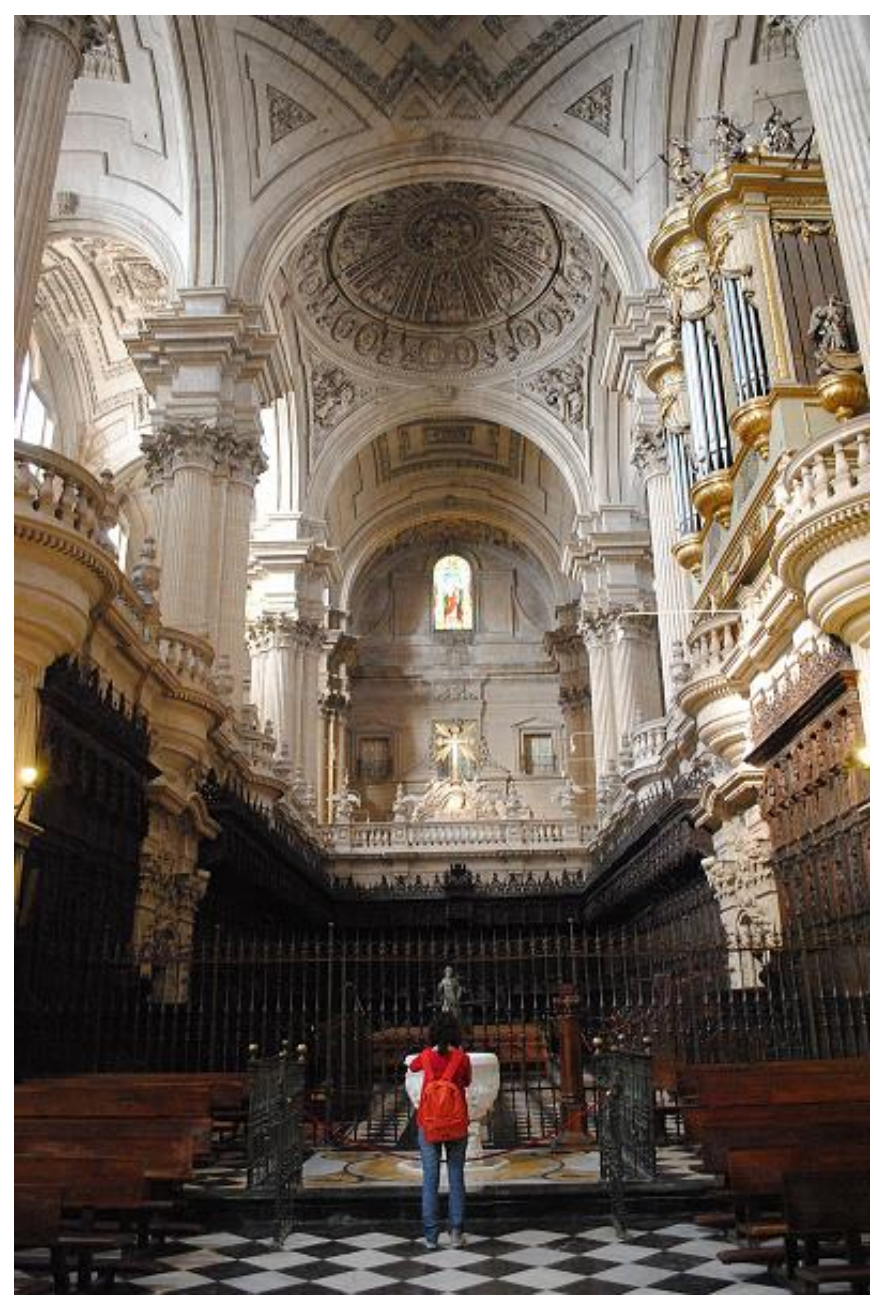

Fig. 9: Vista del Coro de la Catedral de Jaén.

\subsection{LA MÚSICA ESCÉNICA}

Cuando en 1815 ha finalizado la Guerra de la Independencia y aborda la composición de su ópera, Compendio sucinto de la revolución española, Ramón Garay se encuentra en plena madurez. Por ello no es de extrañar que se trate de una de sus obras más logradas. Todo el aprendizaje y asentamiento de su técnica compositiva que supusieron tantas horas de dedicación y ensayo de la música litúrgica en latín y español destinada al culto de la catedral de Jaén sentó las bases para la creación de esta magnífica obra teatral, única incursión del compositor asturiano afincado en Jaén en el mundo del teatro musical. El extenso bagaje al poner música a textos preparó el camino para incorporar formas que ya había cultivado y dominaba a la perfección (estribillos, coplas,

${ }^{37}$ Consultado el 30 de septiembre de 2014. 


\section{PaUlino CAPDEPón Verdú}

arias, recitados, etc.), formas todas ellas que había introducido en sus villancicos, tonadillas o pastorelas; por otro lado, su dedicación sinfónica posibilitó un amplio conocimiento de la técnica orquestal, como lo demuestra esta ópera ${ }^{38}$. Básicamente, la ópera -dedicada a Fernando VII-constituye una obra de carácter propagandístico, destinada a ensalzar el valor de los españoles frente a los ocupantes franceses, al mismo tiempo que se enaltece el papel desempeñado por la monarquía y la religión católica en la defensa de la nación española, tal como ha señalado acertadamente Juan Pablo Pacheco Torres (2010: 189) ${ }^{39}$.

\subsection{LA OBRA SINFÓNICA}

A pesar de que en España se tenía conocimiento del quehacer sinfónico europeo, sin embargo los compositores españoles del siglo XVIII no se prodigaron en el cultivo de la sinfonía, prevaleciendo los géneros vocales tanto en latín como en español así como las obras instrumentales a solo (teclado, guitarra, arpa). Por tal razón y debido al carácter inhabitual en la música española de aquella época, sobresale la producción sinfónica de Ramón Garay. Su primera sinfonía data de 1790 y al año siguiente se remontan las cinco siguientes, si bien entre 1792 y 1797 abandonó la composición de nuevas sinfonías. Retomó esta actividad en 1797, cuando compuso la Séptima Sinfonía y en 1817, año en que compuso las tres últimas (Jiménez: 1996: IX.) ${ }^{40}$. Si el Oratorio al Santísimo suponía una clara muestra de la influencia clásica centroeuropea, lo mismo puede afirmarse de sus diez sinfonías, empleando una instrumentación similar a las sinfonías de la primera etapa de Haydn, a base de dos oboes o flautas, fagot, dos trompas, violines primeros y segundos, viola y acompañamiento, incluyendo este último el contrabajo y el continuo.

Desde el punto de vista cronológico, estas 10 sinfonías están compuestas en 3 etapas: las seis primeras fueron compuestas entre 1790 y 1791, cuando Garay apenas llevaba tres años al frente del magisterio giennense. Las experiencias vividas durante su etapa de estudios con Lidón fueron sin duda determinantes de esta temprana dedicación sinfónica: cinco de estas seis sinfonías presentan una instrumentación similar a las sinfonías de la primera etapa de Haydn, a base de dos oboes, fagot, dos trompas, violines primeros y segundos, viola y acompañamiento, incluyendo este último el contrabajo y el continuo. De 1797 data la Séptima Sinfonía, tras seis años de silencio; en esta sinfonía retorna Garay a la plantilla habitual de dos oboes, dos trompas y sección de cuerda. Por último y después de que hayan transcurrido veinte años sin dedicación a la sinfonía, surgen en 1817 las tres últimas sinfonías: así pues y cuando contaba con 56 años, nacieron las Sinfonías $8^{a}, 9^{a}$ y $10^{a}$, sinfonías que muestran una dotación distinta a las anteriores en lo que se refiere a la madera, pues las tres incorporan un fagot y dos clarinetes, instrumentos también presentes en el último Mozart, lo cual prueba hasta que punto estaba Garay al tanto de la música orquestal centroeuropea.

\footnotetext{
38 Véanse los artículos de Jiménez, 2008 y Pacheco Torres 2008.

39 Asimismo véase Pacheco Torres 2008a.

40 Asimismo consúltese Jiménez 2011, 2011a.
} 


\section{LA TRANSICIÓN AL SIGLO XIX EN LA CATEDRAL DE JAÉN: \\ EL MAESTRO DE CAPILLA RAMÓN GARAY (1761-1823)}

\section{CONCLUSIONES}

A pesar de los avances en el conocimiento de la vida y obra del maestro asturiano Ramón Garay, todavía es necesario seguir profundizando en la significativa aportación musical de este compositor, posiblemente uno de los más prolíficos autores de su tiempo. Dotado de una sólida preparación, adquirida en Oviedo con Joaquín Lázaro y en Madrid con José Lidón, muy joven estuvo en disposición de poder competir por uno de los cargos más emblemáticos en la España de su tiempo: el magisterio de su capilla de la catedral de Jaén. Allí hará frente a las responsabilidades habituales de un maestro de capilla en aquella época: la composición, ensayo e interpretación de nuevas obras destinadas a solemnizar el culto en la catedral giennense; la enseñanza musical de los mozos de coro, la supervisión en las admisiones de nuevos músicos, etc. pero al mismo tiempo los últimos años del siglo XVIII y primeros años del siglo XIX contemplan asimismo la impotencia del maestro Garay para detener el imparable proceso de decadencia que afectó no sólo a Jaén sino a la mayor parte de las instituciones eclesiásticas españolas, agravada además por el estallido de la Guerra de la Independencia en 1808. Pese a ello, no le impidió desplegar una incesante actividad artística que se tradujo además en la composición de diez sinfonías, un género apenas cultivado por la música española, lo que hace de estas obras un hito singular de nuestra historia musical por lo que viene a significar del conocimiento del repertorio sinfónico clásico procedente de Centroeuropa en nuestro país.

\section{BIBLIOGRAFÍA}

AA. VV. (1987). Historia de la Música, 12 vols. Madrid: Turner.

AA. VV. (1993). Catálogo del archivo de música del Palacio Real de Madrid. Madrid: Patrimonio Nacional.

Abraham, G. (1986). Historia universal de la música. Madrid: Taurus.

Alier, R. (1985). "Notes sobre la música de Haydn a la Barcelona del segle XVIII”. Butlletí de la Societat Catalana de Musicologia, no 2, pp. 41-48.

Andioc, R. (1987). Teatro y sociedad en el Madrid del siglo XVIII. Madrid: Editorial Castalia.

Anglés, H. (1941). La música española desde la Edad media hasta nuestros días. Barcelona: Biblioteca de Catalunya.

Anglés, H. (1965). "La música en España”, en Johannes Wolf: Historia de la música, con un estudio crítico de historia de la música española por Higinio Anglés, $4^{\mathrm{a}}$ ed., revisada y ampliada por José Subirá. Barcelona: Editorial Labor. 


\section{Paulino CAPDEPón Verdú}

Aparisi, J. (2008). "Recepción histórica de la música eclesiástica de Joseph Haydn en los archivos musicales catedralicios de la Comunidad Valenciana”. Anuario Musical, no 63, pp. $97-152$.

Arana, J. A. (1976). Música vasca. San Sebastián: Caja de Ahorros Municipal.

Arias del Valle, R. (1981). "Avilés en la música de la S. I. Catedral de Oviedo". Studium ovetense, IX, pp. 159-167.

Arias del Valle, R. (1982). "Ramón Garay, Maestro de Capilla". Papeles de Música, no 17.

Arias del Valle, R. (1990). La orquesta de la Santa Iglesia Catedral de Oviedo (1572-1933).

Oviedo: Instituto de Estudios Asturianos.

Baragaño, R. (2008). "Ramón Garay (1761-1823), músico y compositor avilesino". El Comercio, 8 de diciembre de 2008.

Beltrando-Patier, M. C. (ed.) (1996). Historia de la música: la música occidental desde la edad media hasta nuestros días. Madrid: Espasa-Calpe.

Boyd, M. y Carreras, J. J. (eds.) (2000). La música en España en el siglo XVIII. Madrid: Cambridge University Press.

Burkholder, J. P., Grout, D., y Palisca, C. (2015). Historia de la música occidental. Madrid: Alianza Editorial.

Cañada, S. (ed.) (1970-1999). Gran Enciclopedia Asturiana, Oviedo.

Capdepón, P. (2006). "Mozart y la música española del siglo XVIII”, en Mozart: 250. En el 250 aniversario del nacimiento de Mozart, pp. 39-44. Granada: Orquesta Ciudad de Granada.

Capdepón, P. (2007). "Vibrationen, die die Ankunft Mozarts ankündigen. Mozartrezeption im Spanien des 18. Jahrhunderts", en A. Kreutziger-Herr (ed.): Mozart im Blick: Inszenierungen, Bilder und Diskurse, pp. 259-264. Colonia: Böhlau Verlag.

Capdepón, P. (2011). "Die Rezeption der Opern Mozarts in der ersten Hälfte des 19. Jahrhunderts und die Rolle des spanischen Sängers und Komponisten Manuel García (1775-1832)", Mozart-Jahrbuch, pp. 141-160.

Capdepón, P. (2011a). "Ramón Garay (1761-1823), maestro de capilla de la catedral de Jaén", Cuadernos de Ilustración y Romanticismo. Revista del Grupo de Estudios del siglo XVIII, $\mathrm{n}^{\mathrm{o}} 17$. 


\section{LA TRANSICIÓN AL SIGLO XIX EN LA CATEDRAL DE JAÉN: \\ EL MAESTRO DE CAPILLA RAMÓN GARAY (1761-1823)}

Capdepón, P. (2012). "La primera recepción de la música de Mozart en España (17871830)". Comunicación del Conocimiento. Anuario cientifico de la Universidad Isabel I, vol. I, pp. 21-39.

Capdepón, P. (2012a). La música en la Colegiata de Santa María la Mayor de Talavera de la Reina durante el siglo XVIII. Talavera de la Reina: Ayuntamiento.

Capdepón, P. y Pastor, J. J. (eds.) (2016). Mozarty España. Vigo: Academia del Hispanismo.

Capdepón, P. (2016). El compositor asturiano Ramón Garay (1761-1823). Oviedo: Fundación María Cristina Masaveu.

Casares, E. (1980). La música en la catedral de Oviedo. Oviedo: Servicio de publicaciones de la Universidad.

Casares, E. (ed.). Francisco Asenjo Barbieri: Biografías y documentos sobre música y músicos españoles (Legado Barbieri), vol. I. Madrid: Fundación Banco Exterior, 1986.

Cepeda Adán, J. (2001). Madrid de villa a corte. Madrid: Fundación Universitaria Española.

Fernández García (dir.) (1993). Historia de Madrid, pp. 291-330. Madrid: Editorial Complutense.

Chase, G. (1944). La música de España. Buenos Aires: Librería Hachette.

Dahlhaus, C. (ed.) (1985). Neues Handbuch der Musikwissenschaft, 5. Die Musik des 18. Jahrbunderts. Laaber: Laaber-Verlag.

\section{Diario de Madrid.}

Díez, M. (2003). "Las siete palabras de Cristo en la cruz de Franz Joseph Haydn: un caso paradigmático de mecenazgo musical de la nobleza”. Revista de Musicología, vol. 26-2, pp. 491-512.

Dufourc, N. (2003). Breve Historia de la Música. Madrid: Fondo de Cultura Económica.

Fernández García, A. (dir.) (1993). Historia de Madrid. Madrid: Editorial Complutense.

Fernández García, A. (2008). Madrid, de la Prehistoria a la Comunidad Autónoma. Madrid: Consejería de Educación.

Filgaira, M. (2011). “Genealogía de Ramón Fernando Garay Álvarez (1761-1823), contemporáneo de Haydn y seguidor de su estilo en España: las últimas pruebas de limpieza de sangre a un maestro de capilla en la Catedral de Jaén”. Revista $M A R, \mathrm{n}^{\circ} 1$, 


\section{PaUlino CAPDEPón Verdú}

pp. 149-176.

Finscher, J (ed.). Die Musik in Geschichte und Gegenwart. Bärenreiter: Kassel 1994-2007.

"Franz Joseph Haydn y el Clasicismo musical en España” (2011). Número monográfico de Revista MAR. Música de Andalucía en la Red, $\mathrm{n}^{\circ}$ 1. Disponible en: http://mar.ugr. es/static/MAR_Revista/*/1

Gallego, A. (1997). Historia de la Música II. Madrid: Historia 16.

Garbayo, J. (2013). "Estilo galante y sinfonías de F. J. Haydn en la capilla de música de la catedral de Santiago de Compostela durante el magisterio del Melchor López (17831822): la renovación del repertorio instrumental”. Anuario Musical, no 68, pp. 263-292.

García Laborda, J. M. y Arteaga, E. (eds.) (2008). En torno a Mozart: reflexiones desde la Universidad. Salamanca: Universidad de Salamanca.

García Marcellán, J. (1938). Catálogo del Archivo de música del Palacio de Oriente. Madrid: Editorial del Patrimonio Nacional.

Garrido, T. (2011). Notas al programa de mano del concierto "Oratorio al Santísimo, de Ramón Garay. XXI Festival de Arte Sacro, Madrid. Disponible en: http://www.madrid.org/ artesacro/2011/espacios/01.html

González Pérez, Á. (1980). "Homenaje a don Juan Andrés Lombide y Mezquía, célebre organista de la catedral de Oviedo en el siglo dieciocho”. Boletín del Real Instituto de Estudios Asturianos, vol. 34, no 101, pp. 655-668.

González Pérez, Á. (1981). "Don Andrés Lombide Mezquía, distinguido organista que fue de la Catedral de Oviedo". Boletin de la Real Sociedad Vascongada de Amigos del País, vol. 37, 3-4.

Gosálvez Lara, C. (2009). “Haydn visto por los españoles”. Scheræo, n 239, pp. 124-128.

Griffths, P. (2009). Breve Historia de la música occidental. Madrid: Akal, 2009.

Hamilton, M. N. (1937). Music in Eighteenth Century Spain. Nueva York: Urbana.

Honneger, M. (ed.) (1994). Diccionario biográfico de los grandes compositores de la Música. Madrid: Espasa Calpe.

Honolka, K. (ed.) (2005). Historia de la música. Madrid: Edaf.

Jiménez Cavallé, P. (1987). "En torno a la vida y obra del maestro de capilla de la Catedral 


\section{LA TRANSICIÓN AL SIGLO XIX EN LA CATEDRAL DE JAÉN: \\ EL MAESTRO DE CAPILLA RAMÓN GARAY (1761-1823)}

de Jaén, autor de diez sinfonías, Ramón Garay”. Códice, 2, pp. 15-23.

Jiménez Cavallé, P. (1987a). "Organistas y Maestros de Capilla de la Catedral de Jaén. Cronología”. Senda de los Huertos, 6, pp. 67-72.

Jiménez Cavallé, P. (1988). "Ramón Garay, maestro de capilla de la catedral de Jaén, autor de 10 sinfonías. Nuevas aportaciones”, en Historia, Arte y Actualidad de Andalucía, pp. 403-420. Córdoba. Jiménez Cavallé, P. (1991). La música en Jaén. Jaén: Diputación Provincial de Jaén.

Jiménez Cavallé, P. (1996). Ramón Garay (1761-1823). Sinfonías n 5, 8, 9 y 10. Madrid: Instituto Complutense de Ciencias Musicales.

Jiménez Cavallé, P. (1998). "Los maestros de capilla de la catedral de Jaén”. Boletín de la Confederación Andaluza de Coros, pp. 3-6.

Jiménez, P. (2000). “Garay, Ramón”, en Emilio Casares (dir.). Diccionario de la música española e hispanoamericana, vol. V, pp. 376-379. Madrid: Sociedad General de Autores y Editores.

Jiménez Cavallé, P. (2008). “Ramón Garay, un asturiano en Jaén”, en Notas al programa de mano de la ópera 'Compendio sucinto de la revolución española', XII Festival de Música Antigua de Úbeda y Baeza.

Jiménez Cavallé, P. (2009). Ramón Garay (1761-1823). Sinfonias n 1, 2, 3, 4, 6 y 7 . Madrid: Instituto Complutense de Ciencias Musicales, Madrid.

Jiménez Cavallé, P. (2009a). "La capilla musical de la catedral de Jaén y su evolución histórica". Elucidario: Seminario Bio-bibliográfico Manuel Caballero Venzalá, no 7, pp. 97117.

Jiménez Cavallé, P. (2010). Documentario Musical de la Catedral de Jaén. II Documentos de Secretaría. Granada: Centro de Documentación Musical de Andalucía.

Jiménez Cavallé, P. (2011). Las sinfonías de Garay. Ejemplo de Clasicismo en España. Análisis musical. Jaén: Servicio de Publicaciones de la Universidad de Jaén.

Jiménez, P. (2011a). Ramón Garay (1761-1823). Un clásico, autor de 10 sinfonias. Jaén: Universidad de Jaén.

Juliá, S., Segura, C. y Ringrose, D. R. (1998). Madrid, historia de una capital. Madrid: Alianza 


\section{PaUlino CAPDEPón Verdú}

Editorial.

Kastner, S. (1941). Contribución al estudio de la música española y portuguesa. Lisboa: Atica.

Keefe, S. P. (ed.) (2009). The Cambridge History of Eighteenth-Century Music. Cambridge: Cambridge University Press.

Klauk, S. (2011). "Dos cuartetos de Joseph Haydn para el Duque de Alba", Anuario Musical, $\mathrm{n}^{\circ}$ 66, pp. 159-2011.

Kuhn, L. D. (ed.) (2007). The Concise Baker's Biographical Dictionary of Musicians, 9a edición. Nueva York: Schirmer Books.

La Alhambra.

Le Bordays, C. (1978). La música española. Madrid: Edaf.

Leza, J. M. (ed.) (2014). Historia de la música en España e Hispanoamérica 4: Siglo XVIII. Madrid: Fondo de Cultura Económica.

Llordén, A. (1976-1977). "Notas históricas de los maestros de capilla en la colegiata de Antequera". Anuario Musical, vol. 31-32, pp. 115-155.

Llordén, A. (1978-1980). "Maestros organistas de la colegiata de Antequera". Anuario Musical, vol. 33-34, pp. 51-79.

López-Calo, J. (2012). La música en las catedrales españolas. Madrid: Instituto Complutense de Ciencias Musicales.

Martín Moreno, A. (1981). "La música en Andalucía hasta el siglo XIX” (1981), en Historia de Andalucía, pp. 357-468. Madrid-Barcelona: Planeta.

Martín Moreno, A. (1983). "La música culta andaluza". A Tempo. Revista de Música, pp. 1428.

Martín Moreno, A. (1984). "La Música Andaluza", en Historia de Andalucía: La Cultura Andalura, Música y Arte, vol. IX, pp. 11-150. Madrid: Planeta.

Martín Moreno, A. (1985). Historia de la música española. 4. Siglo XVIII. Madrid: Alianza Editorial, Madrid.

Martín Moreno, A. (1985a). Historia de la Música andaluza. Sevilla: Editoriales Andaluzas Unidas.

Martín Moreno, A. (1986). "La música culta andaluza”, en Andalucía, pp. 433-457. Sevilla: 


\section{LA TRANSICIÓN AL SIGLO XIX EN LA CATEDRAL DE JAÉN: \\ EL MAESTRO DE CAPILLA RAMÓN GARAY (1761-1823)}

Editoriales Andaluzas Reunidas.

Martín Moreno, A. (2000). "La Música andaluza”, en Gran Enciclopedia Andaluza del siglo XXI, vol. 6, pp. 93-146. Sevilla: Editorial Tartessos.

Medina Crespo, A. (1997). "Órgano de la Catedral de Jaén". Boletín del Instituto de Estudios Giennenses, 167, pp. 309-344.

Medina Crespo, A. (1999). "Archivo musical", en Fondos documentales del Archivo Histórico diocesano de Jaén, vol. I, pp. 541-739. Jaén: Obispado de Jaén.

Medina Crespo, A. (1999a). "Cantatas y villancicos a la Purísima, del maestro Lapuente”. Diario Jaén, 5 de diciembre de 1999.

Medina Crespo, A. (2000). “Los cantos eucarísticos en la Catedral de Jaén”. Expiración, no 36.

Medina Crespo, A. (2002). "Juan Manuel Lapuente: Miserere a 18”. Boletin del Instituto de Estudios Giennenses, 182, pp. 353-406.

Medina Crespo, A. (2008). Villancicos barrocos en la catedral de Jaén. Jaén: Ediciones Blanca.

Medina Crespo, A. (2009). Catálogo del archivo de música de la Santa Iglesia Catedral de Jaén. Sevilla: Consejería de Cultura.

Melgares Raya, J. (1977). “Apuntes sobre Historia del Archivo de la Catedral de Jaén”. Boletín del Instituto de Estudios Giennenses, XCI, pp. 47-68.

Melgares Raya, J. (1977). “Archivo capitular de la Catedral de Jaén”. Boletín del Instituto de Estudios Giennenses, no 183, pp. 495-510.

Mila, M. (1998). Breve Historia de la Música. Barcelona: Península.

Mitjana, R. (1920). "Espagne”, en Albert Lavignac: Histoire de la Musique, vol. IV. París: Librairie Delagrave (edición española: Historia de la música en España, Centro de Documentación Musical, Madrid 1994).

Montero García, R. (2011). "La música de Franz Joseph Haydn en España: recopilación, catalogación e interpretación de las fuentes musicales conservadas en Madrid hasta 1833" (Tesis doctoral). Granada: Universidad de Granada.

Montero García, R. (2011a). 'La música de Franz Joseph Haydn conservada en la Biblioteca del Real Conservatorio Superior de Música de Madrid (fuentes anteriores a 


\section{PAULINO CAPDEPón Verdú}

1834). Recopilación y catalogación de las fuentes musicales”. Revista de Musicología, vol. 34-1, pp. 273-299.

Muñoz y Garnica, M. (1857). Vida y escritos de D. José Martínez de Mazas. Jaén: Imprenta de López y Cia.

Pacheco Torres, J. P. (2008). "Fuentes y estructura del Compendio", en Notas al programa de mano de la ópera 'Compendio sucinto de la revolución española'. XII Festival de Música Antigua de Úbeda y Baeza.

Pacheco Torres, J. P. (2008a). "Música patriótica en la Catedral de Jaén. 'Compendio sucinto de la revolución española', una obra sobre la Guerra de la Independencia Española (1808-1814)". Giennium: revista de estudios e investigación de la Diócesis de Jaén, vol. 11, pp. 323-364.

Pacheco Torres, J. P. (2008b). Música patriótica teatral y escénica de la Guerra de la Independencia española, Diploma de Estudios Avanzados (director: Antonio Martín Moreno). Granada: Universidad de Granada.

Pacheco Torres, J. P. (2010). "El Compendio sucinto de la revolución española (1815) de Ramón Garay (1761-1823)", Cuadernos de arte de la Universidad de Granada, no 41, pp. 189-212.

Pacheco Torres, J. P. Compendio sucinto de la revolución española (Ramón Garay, 1815). Poema político-musical sobre los acontecimientos de la Guerra de la Independencia española, colección "Patrimonio Musical". Granada: Universidad de Granada y Centro de Documentación Musical de Andalucía, en prensa.

Páez-Camino, F. (1994). Aproximación histórica a la Comunidad de Madrid. Vol. II: De la Ilustración a nuestro tiempo. Madrid: Consejería de Educación y Cultura de la Comunidad de Madrid.

Pena, J. y Anglés, H. (1954). Diccionario de la Música Labor, 2 vols. Barcelona: Editorial Labor.

Polo, M. (2011). Historia de la Música. Santander: Ediciones de la Universidad de

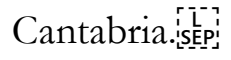

Quintanal, I. (1983). La música en la Catedral de Oviedo en el siglo XVIII. Oviedo: Centro de Estudios del Siglo XVIII. 


\section{LA TRANSICIÓN AL SIGLO XIX EN LA CATEDRAL DE JAÉN: \\ EL MAESTRO DE CAPILLA RAMÓN GARAY (1761-1823)}

Radigales, J. (1998). "Wolgang Amadeus Mozart debuta en España”. Ópera actual, no 30, pp. $32-33$.

Radigales, J. (2006). Mozart a Barcelona. Recepció operística (1789-2006). Barcelona Publicacions de l'Abadia de Montserrat.

Rebatet, L. (2012). Una bistoria de la música: de los orígenes a nuestros días. Madrid: Omega Ediciones.

Ricart Matas, J. (1956). Diccionario Biográfico de la Música. Barcelona: Editorial Iberia

Ringrose, D. R. (1985). Madrid y la economía española, 1560-1850. Madrid: Alianza Universidad.

Ruiz Tarazona, A. (2018). España en sus grandes músicos. Madrid: Siruela.

Sadie, S. (ed) (2001). The New Grove Dictionary of Music and Musicians. Londres: Macmillan Press.

Salazar, A. (1972). La música de España, 2 vols. Madrid: Espasa Calpe.

Schmierer, E. (2015). Epochen der Musik, 4. Die Musik des 18. Jabrbunderts. Laaber: LaaberVerlag.

Solar-Quintes, N. Á. (1947). "I Las relaciones de Haydn con la casa de Benavente. II Nuevos documentos sobre Luigi Boccherini. III Manuel García, íntimo. Un capítulo para su biografía”. Anuario Musical, no 2, pp. 81-98.

Soriano Fuertes, M. (1855-1859). Historia de la música española desde la venida de los fenicios hasta el año de 1850, 4 vols. Barcelona-Madrid: Imprenta de Narciso Ramírez (edición moderna: Madrid: Instituto Complutense de Ciencias Musicales, 2007, 2 vols.).

Suárez, Constantino (1936-1959). Escritores y artistas asturianos: indice bio-bibliográfico. Oviedo: Gráficas Summa.

Subirá, J. (1953). Historia de la música española e hispanoamericana. Barcelona: Salvat.

Temes, J. L. (2010). "Ramón Garay: las 10 sinfonías". Notas al CD Ramón Garay, 1761 1823: Las 10 Sinfonías. Orquesta de Córdoba (dir. de José Luis Temes), 3 CD’s, VRS 2099 .

Ureña y Hevia, J. (2005). "Ramón Fernando de Garay y Álvarez (1761-1823)". Crónicas avilesinas, mayo. 


\section{PAUlino CAPDepón Verdú}

Vilar, J. M. (1984). "Una simfonia de Haydn a l'Arxiu de la seu de Manresa". Recerca Musicologica, $\mathrm{n}^{\circ}$ 4, pp. 127-176.

Wellesz, E. y Sternfeld, F. (eds.) (1973). The New Oxford History of Music. Volume VII. The Age of Enlightment 1745-1790. Oxford: Oxford Univetsity Press.

Wyn Jones, D. (2003). “Sinfonías austriacas en el Palacio Real de Madrid”, en M. Boyd y J. J. Carreras (eds.), La música en España en el siglo XVIII, pp. 145-166. Madrid: Cambridge University Press.

Fecha de recepción: 24/05/2018

Fecha de aceptación: 14/07/2018 